\title{
Conception of domestic final energy delivery including EV charging in terms of integrated multi-modal grid expansion
}

\author{
DANIELA VORWERK and DETLEF SCHULZ \\ Faculty of Electrical Engineering \\ Electrical Power Systems \\ Helmut Schmidt University / University of the Bundeswehr Hamburg \\ Holstenhofweg 85, 22043 Hamburg \\ GERMANY
}

\begin{abstract}
Regarding the energy transition in terms of ecological and economical aspects, also the security in supply, safe and reliable operation and the desired ability to store renewable generated excess electrical power play a role in future grid expansion strategies. To support and release the electric grid, integrated energy systems, characterized by sector-coupling between the energy sectors electricity, gas and heat, picture an approach to increase the storage and transmission capacity of a whole energy system. Concerning the demand side, it also has to be kept in consideration that not every kind of desired final energy has to be necessarily electrical. So, power has to be supplied in the appropiate kind to satisfy the consumers' requirements. Within the following contribution a holistic methodology is presented which is able to deal with various compositions of domestic technical endowment for residential areas to acquire knowledge about necessary delivery power of the main three energy sectors. The types of final energy, that will be considered, are electricity for basic services and personal electric vehicle usage and heat for heating space and tap water. The desired kind of final energy can be delivered by on-point power transformation, so the methodology includes several possible types of appliances and endowment. With the nearly infinite possible composition and input options, it is transferable to residential areas of different dimensions and mirrors the high versatility and flexibility of the domestic sector as a decisive consumer, preliminary for later analysing e.g. whole urban areas and network infrastructures including the generators' side. It serves as a tool to investigate, in what manner power delivery characteristics change, when the configuration of final energy devices in the domestic sector is altered and what conclusions have to be drawn by the energy providers and especially the transmission system operators for electricity, gas and heat, in terms of integrated grid expansion strategies. It can either be used as a "green meadow" approach for newly built development areas or for enlargement of already existing housing areas. Additionally to a detailed explanation of the methodology's structure, some configuration scenarios are defined and the algorithm is executed for an exemplary residential area. Furthermore, some relevant objectives, like primary energy input, system efficiency or capital expenditure are declared to serve as rating criteria for evaluation of the investigated composition scenarios. The presented methodology provides a basis for (multi) criteria optimization of expansion strategies for integrated infrastructures in further research.
\end{abstract}

Key-Words: - multi-modal energy systems, sector-coupling, integrated grid expansion, domestic power supply, energy transformation, electromobility

Received: June 3, 2020. Revised: August 6, 2020. Accepted: September 6, 2020. Published: September 15, 2020.

\section{Introduction}

To successfully manage the energy transition, various interdisciplinary questions and challenges have to be faced. In terms of decentralized renewable energy supply which is mainly produced in form of electricity from wind or solar power, electric grids may get overloaded due to slower grid expansion compared to the fast dissambly of renewable generators. Furthermore, in terms of the estimated growing electromobility sector [1], the whole electric infrastructure has to face this development and to challenge the strongly growing electrification of the transportation sector by ad- equate expansion strategies and increasing transmission capacities. Besides, ensuring the power balance between generation and demand is always a main part in network operation. Electricity itself is not storable but has to be transformed to other kinds of less volatile energy carriers [2]. Unlike the electric power which consists of moving electrons, gas implies inner chemical energy which can be retrieved by combustion at the desired point of time. In addition, gas grids operate in a much longer time range with higher inertia than the electric grids and due to the capacity of pipeline infrastructure they provide the ability to store 
energy for longer time periods [3]. Concerning the already distinctive infrastructure of natural gas transport in Europe, there is the opportunity to release the electric sector by using the high potential of sectorcoupling. Coupling between the main different energy sectors, electricity, gas and also heat increases the storage capability, flexibility and redundancy of a full energy system [4, 5]. In terms of occuring interdependencies between the grids of energy carriers with different physical behavior, grid expansion strategies have to be transferred from seperated to integrated multi-modal strategies.

The requirements of grid expansion are manifold and cover technical, economical and ecological aspects. Some are

- security in supply

- technical safety

- reliability

- resilience

- environmental compatibility

- economic viability

- efficiency

and depict the basis of a working and socially accepted energy system. The effectiveness of grid expansion stretegies could be rated by different values and criteria, the priority may differ, regarding subjective points of view of society, grid operators or environmental associations. Some rating criteria to evaluate energy systems are pictured in 3 .

\section{Primary energy input Capital expenditure

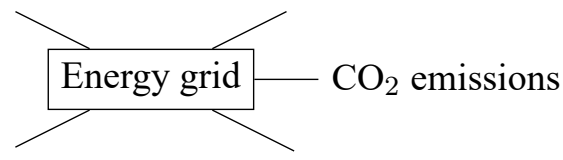 \\ Operation costs \\ Transition losses}

Fig. 1: Criteria of grid expansion and operation.

Some objectives and targets of expansion strategies fit well together and complement each other, others may be independent or opposed to each other.

Corresponding research To successfully execute an "integrated energy transition", there is need for action in every sector of an energy system, also regarding quarters and buildings [1]. In [1], the definition of "integrated energy system" is not only related to the three wired energy infrastructures, but also uses the term "sector" and "sector-coupling" for coupling different consumer structures like industry, transportation and domestic sector. The interdependency between all the components in energy systems require smart and interdisciplinary methods for dealing with the future development of the energy transition [1]. Some publications regarding multi-modal grid structures and sector-coupling between different energy sectors deal with coupled load flow methods as in [6, 7, 8], optimization strategies in integrated structures [9, 10, 11] or quasi-dynamic interactions between electric and heating grid in [12]. In [13] a methodology to combine the sectors electricity, heat and mobility in terms of cost-effective decarbonization in a holistic approach is presented. In [14] a coordinated integrated operation is investigated and [15] focuses on the design of multi-modal energy systems under consideration of components' part-load efficiencies. In [16] a cost-optimization comparison between electricity storage and sector-coupling is made with discovering high benefits of sector-coupling. In [17] the synergies between sector-coupling and transmission re-inforcement is investigated. In addition to that research, the presented method shall contribute to the topic of multi-modal structures regarding especially the demand side. Because of the various kinds of existing end devices for residents' needs, the domestic sector offers high potential for energy transformation and so to say "sector-coupling at home". For example, today's fulfillment of space heating demand is not anymore only given by conventional gas or oil-fired boilers, but also by electrical heat pumps [18] or fuel cell systems [19]. The power supply for residences in development areas from zero on with a "green meadow" approach on one hand enables nearly infinite possibilities to the user of the method. On the other hand, the supply configurations for extended residential areas can be chosen in a grid-assistive way to utilize available capacities and release the overloaded ones. The technical possibilities and smart configurations of end devices can support and accommodate the suppliers and so the grids itself. By trial of the presented method, different configurations can be investigated and conclusions can be drawn for the three energy sectors electricity, gas and heat which can be evaluated by different criteria. The research regarding domestic consumer behavior often focuses on smart-metering electric devices in single households like in [20, 21, 22] to regulate the demands for generating a grid-assistive load flow. Within the following method the demand side management in terms of affecting consumer behavior is not regarded, only the installation of appliances for final energy supply can be managed and the results and conclusions can be analyzed after the method's execution. In [23] the domestic sector is examined quite detailed with individual defined devices in households. Within the here presented manuscript, the basic elec- 
tric load is not partitioned to single electric devices but personal charging of electric vehicles is taken into consideration and this does depict a relevant difference in domestic electric demand in contrast to conventional electric basic load. In [24, 25, 26] full urban regions and their energetical supply are taken into consideration.

Motivation The research within the following manuscript serves as a contribution to bring the power demand's development of the domestic sector on one side and grid expansion strategies on the other side together in an integrated point of view, utilizing the multipurpose power delivery within households to support grid expansion by the aspects mentioned in 3 and further.

Some generally questions according to the field are formulated as a motivation to the here presented investigation:

- What are the possibilities to supply domestic final energy and what does it mean for the three sectors electricity, gas and heat?

- How high is the potential of increasing flexibility in an energy system by using the high versatility of power transformation in the domestic sector?

- What configurations of technical endowment in the domestic sector lead to good boundary conditions in terms of various aspects of grid expansion strategies?

- How can forecasting of consumer's final energy consumption be involved into future integrated grid expansion strategies?

- What capacities for new built electric lines, or gas and district heating pipes are necessary for domestic development areas dependent on the residence's technical endowment and how can it be planned and designed in a multi-modal way, taking perceptions of the three grid operators into account?

- How can the configuration of domestic end devices be designed in a smart way to use available structure capacities and not endanger overloading of structures operationg at the limit?

- How can overloaded grid structures be released by retrofitting technical end devices and so change the kind of power supply?

- How can the technical extention of an already existing municipality realized in a grid-assisitive way?
-What consequences for the electric grid result out of higher electrification of the consumers, considering e.g. EV charging and heat pumps? To what extent does it make sense to provide heat electrical and enable private, uncontrolled EV charging?

- What conclusions have to be drawn for the energy grids due to decentralized generation by PVor fuel cells?

- In what kind of regions does it make sense to expand all three energy grids, and where is it more advantageous only to build one or two?

Of course, not all of those questions will or can be answered in detail within this manuscript and least of all for every configuration case or district parameters. Primarily, only exemplary scenarios will be pictured and so the given results are only valid for the existing parameters and boundary conditions of the examples. But the presented methodology itself should assist users to draw conclusions and deduce answers to the questions for concrete use cases.

In the following manuscript the main considered ways of power transformation are explained at the beginning in section 2. Thereupon, the general conception methodology of final energy delivery in the domestic sector is explicitly described in section 3 . Some configuration scenarios are defined and results for an exemplary execution of the method will be presented and discussed in 5. Also rating criteria are established as objectives to evaluate chosen configurations regarding different aspects. Conclusions and topics for further research based on the given methodology are treated in the end.

\section{Forms of power transformation}

There are several methods for transforming electrical energy into chemical energy and vice versa [27, 28]. The ability to transform certain energy carriers into others leads to more flexibility in operating energy systems and also more possibilities to store excess power [5]. The most important ways of energy transformation and the corresponding technical devices considered within this investigation are briefly mentioned in the following sections.

\subsection{Gas-to-Power}

The energy transformation from gas to power is well established. In conventional power generation, the chemical energy of a fuel is used to initiate and maintain a combustion reaction to highly increase the process fluid's enthalpy. The process fluid runs a cycle consisting of turbo machinery and a generator for electrical output [27]. Nowadays, gas power plants 
are fed by natural gas out of the transition infrastructure [27]. Those power plants are usually attached at the high voltage level. However, this particular area is not part of this work which, consequently, does not feature any analysis of cyclic processes.

Another way to transform gas to electrical power is the fuel cell (FC) in which a "cold combustion" is realized. Inside a fuel cell electric power is produced by a redox-reaction between hydrogen and oxygen [19]. The overall static electrical efficiency $\eta_{\mathrm{FC} \text {,el }}$ of a fuel cell shall be defined as

$$
\eta_{\mathrm{FC}, \mathrm{el}}=\frac{P_{\mathrm{FC}, \mathrm{el}}}{\dot{E}_{\mathrm{NG}}}=\frac{P_{\mathrm{FC}, \mathrm{el}}}{\dot{m}_{\mathrm{NG}} \cdot H_{\mathrm{i}}}
$$

with the electric output $P_{\mathrm{FC}, \mathrm{el}}$, the mass flow of natural gas, $\dot{m}_{\mathrm{NG}}$, and the inferior heating value , $H_{i}$, already regarding the reformation efficiency for transforming natural gas to hydrogen and the electric components' efficiencies. Today's existing fuel cell systems show an electrical efficiency of about $\approx 40 \%$, based on a hydrogen-feed without the reformation step [27].

\subsection{Gas-to-Heat}

The usage of a fuel's chemical energy as heat is a longknown principle and is realized via exothermic reactions e.g. in combustion motors in vehicles, rankinecycles or the Joule-process [28]. In the light of a future energy system, that does not rely on coal, this work takes into account only natural gas as fuel with less $\mathrm{CO}_{2}$-emissions compared to coal. Nowadays, a lot of households use gas boilers to heat tap water or to feed a heating system for space heating. The possible recoverable heat flow $\dot{Q}_{\mathrm{NG}}$ in a combustion is given by

$$
\dot{Q}_{\mathrm{NG}}=\dot{m}_{\mathrm{NG}} \cdot H_{\mathrm{i}} .
$$

The operation of fuel cells produces some waste heat which can be used further. Regarding the use of combined power and heat using FCs, the maximum usable heat efficiency $\eta_{\text {th }}$ is naturally limited by

$$
\eta_{\mathrm{th}}=1-\eta_{\mathrm{FC}, \mathrm{el}} .
$$

\subsection{Power-to-Gas}

Power-to-Gas is a strategy to transform electrical energy to chemical energy stored in e.g. hydrogen or methane. It is a useful alternative for storing excess electrical output from renewable resources [29]. During times of overproduction, the additional power can be transformed into a less volatile energy carrier. However, on the premise that the average resident is neither willing nor able to produce and store the gas for their own consumption, the concept of Power-toGas is neglected throughout this work.

\subsection{Power-to-Heat}

The transformation of Power-to-Heat is often realized on-site, e.g. by small water boilers or in electrical flow heaters. The recoverable heatflow in form of heated-up fluid (e.g. water) $\dot{Q}_{\mathrm{FH}}$ in a flow heater is defined by

$$
\dot{Q}_{\mathrm{FH}}=\dot{m} \cdot c_{p} \cdot \Delta T=P_{\mathrm{el}} \cdot \eta_{\mathrm{FH}} .
$$

Another technology for the heating of space and tap water can be found in heat pumps. They are able to deliver heat out of the earth or the environment on a low temperature level [28]. The so-called heat pump's $C O P$ ("coefficient of performance") is defined as the ratio of produced heat $Q$ and input energy $W$.

$$
C O P=\frac{Q}{W}
$$

Typical $C O P$-values for heat pumps extracting heat from the ground lie between 4 and 5, whereas heat pumps extracting heat from the environment feature values around $3[18,28]$.

\section{General Methodology}

Within this chapter the general methodology of the conception for final energy delivery in the domestic sector used in this paper is presented and explained in detail. The single calculation steps can be programmed in every kind of software and so be utilized as a tool. Figure 2 pictures the structure scheme of the methodogology, which is divided into the three main levels "final energy demand", "final energy supply" and "power delivery". Firstly, section 3.1 gives a small introduction to the domestic sector and its typical kinds of final energy demand. Secondly, in section 3.2 typical end devices to satisfy domestic needs are presented and the boundary conditions for technical installation configurations within a residential area are defined. In the following section 3.3 the operation of end devices for time-dependent final energy supply is picked out as a central theme. On basis of the existing final energy demands and knowledge of the end devices' power transformation behavior and distribution within the energy system, the necessary input power for the end devices can be determined. Subsequently, the transfer from final energy supply level to the necessary power delivery level for the three wired energy sectors electricity, gas and heat, is derived in section 3.4.

\subsection{Approach of domestic final energy demand}

The modeled residential area consists of $N$ households, whose power demands shall be met at any time. 


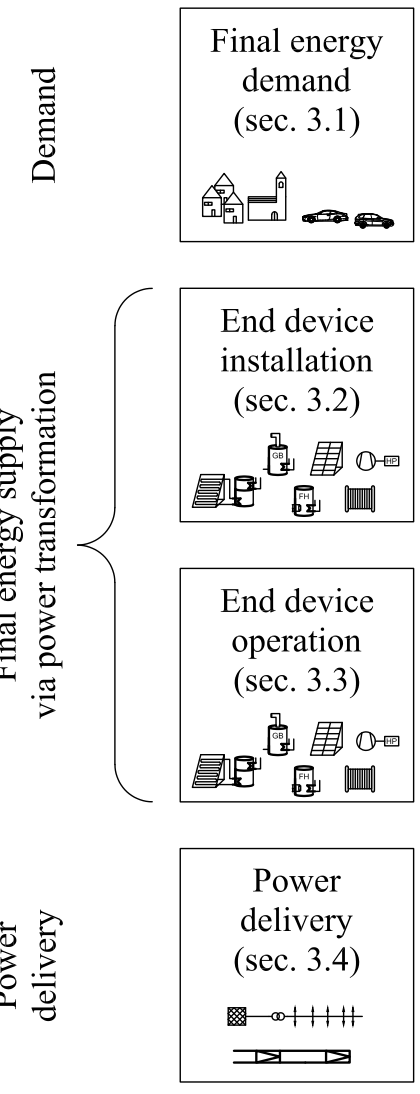

Fig. 2: Structure scheme of the methodology.

The final energy of households can be devided into three main parts: Electric demand, heat for tap water and space heating. The first type of final energy, the electric demand $P_{\mathrm{el}, \mathrm{FE}}$, represents pure electric power which cannot be replaced by any other kind of energy. Within this investigation, the electric demand is divided into two parts: The first part is the conventional electric basic services, $P_{\mathrm{el}, \mathrm{FE}, \mathrm{dom}}$, representing typical electric appliances. Within the domestic sector, they are e.g. the fridge and freezer, oven, vacuum cleaner, TV, radio, lighting, phone charging, notebooks, PCs, tea cooker, washing machine, hairdryer, grid connected electric toys, dishwasher for typical households. Respectively, that appliances also need a small amount of reactive power. Also, the opportunity for charging electric vehicles (EV) at home shall be taken into consideration here and is represented by the term $P_{\text {el,EV}}$.

Second type, $\dot{Q}_{\mathrm{HW}, \mathrm{FE}}$, comes in form of hot water to fulfill hygienic and sanitarily requierements. The third kind of domestic demand, $\dot{Q}_{\mathrm{SH}, \mathrm{FE}}$, is needed fo space heating to keep the residences' inside at an appropriate temperature level. Space heating is the most notable energy demand in the domestic sector. Also there can be no reduction considering simultaenity, because the cold affects the whole region at the same time. Table 1 gives an overview of the three incorporated forms of final energy consumed in the domestic sector.

Table 1: Overview of the types of final energy consumed in the domestic sector.

\begin{tabular}{ll}
\hline FE & Explanation \\
\hline$P_{\mathrm{el}, \mathrm{FE}}=$ & Pure electric power for \\
$P_{\mathrm{el}, \mathrm{FE}, \mathrm{dom}}+P_{\mathrm{el}, \mathrm{EV}}$ & domestic devices and \\
$\dot{Q}_{\mathrm{HW}, \mathrm{FE}}$ & EV \\
$\dot{Q}_{\mathrm{SH}, \mathrm{FE}}$ & Heat power of hot water \\
\hline
\end{tabular}

The power balance for one household with its time-dependent total demand $\dot{E}_{\mathrm{FE}, \text { household }}(t)$ respectively the power balance of the whole residential area has to be ensured at every instant of time $t$.

\subsection{Configuration of technical implementation}

The delivery of different final energy types at each residence can be achieved by various technical devices with diverse feeds of energy carriers. It has to be kept in mind, that there are nearly infinite alternatives of installing devices but the replacement or change in composition or installed capacity from one time step to the next one is not possible without further ado. In the following, a reasonable distribution pattern of such end devices within a the domestic sector is proposed.

\subsubsection{Electric power}

A residence's electric power is usually delivered by a connection to the external electric grid at the low voltage level $(0.4 \mathrm{kV})$ [27]. For the security of supply, every household is connected, so there are $n_{\mathrm{el}, \text { grid }}=N$ connection points to the external electric grid. Additionally, a household may have photovoltaic (PV) cells on their roof for decentralized generation of electricity. The number of households with installed PVpower, $n_{\mathrm{PV}}$, is in the range of zero to $N$. Furthermore, it could be the case that every household could own a small residential fuel cell system which produces electricity as its own small power plant. The number of households with a fuel cell is defined as $n_{\mathrm{FC}}$ with the boundary condition $0 \leq n_{\mathrm{FC}} \leq N$. It is, of course, possible for a household to feature both technologies, $\mathrm{PV}$ and FC.

The mobility of the inhabitants shall be represented with the amount of EV, $n_{\mathrm{EV}}$, in the domestic area which is not naturally limited to an upper level.

\subsubsection{Heating tap water}

Because of hygienic and comfort requirements, tap water is heated up to a pleasurable temperature level, 
so heat power has to be added. This can be realized via electrical flow heaters (FH) $n_{\mathrm{FH}}$, heat pumps (HP) $n_{\mathrm{HP}, \mathrm{HW}}$, combustion of NG in gas boilers (GB) $n_{\mathrm{GB}, \mathrm{HW}}$, a district heating grid connection (DHG) $n_{\text {DHG,HW }}$ or solar thermal (ST) energy. To use solar thermal energy, a hot water storage is necessary to store the not directly used power of sunlight (STS). The number of households with solar thermal and storage technology is defined by $n_{\text {STS }}$. Furthermore, the ability to use the waste heat of a fuel cell to heat up the tap water shall be taken into account. Under the assumption that especially during winter months, the tap water cannot be heated up appropriately only by solar thermal panels so that every household with installed ST is required to have access to an additional energy source. Additionally, it is preconditioned, that every household just uses one of these additional conventional technologies. This leads to the equation

$$
n_{\mathrm{FH}}+n_{\mathrm{HP}, \mathrm{HW}}+n_{\mathrm{GB}, \mathrm{HW}}+n_{\mathrm{DHG}, \mathrm{HW}}+n_{\mathrm{FC}}=N \text {. }
$$

\subsubsection{Space heating}

Especially during winter, reliable space heating is essential for the inhabitants' convinience. Rules and standards regulate the design of heating devices to ensure a minimal inner temperature according to a reference ambient temperature, dependent on the location [30]. For space heating, different technical implementations are used. One of the most widely used is still space heating with a gas fired boiler (GB), with storage and heating system. The number $n_{\mathrm{GB}, \mathrm{SH}}$ of households owning a gas fired boiler for feeding a heating system is in the range of at less zero to maximum $N$.

The number of households using an electrical heat pump (HP) for space heating is defined as the variable $n_{\mathrm{HP}, \mathrm{SH}}$ with its maximum value $N$. Also, it is possible to use the process heat of FCs for space heating [19]. The number of residences with installed fuel cell technology is already defined above. Households without own heat generators need a connection to the district heating grid (DHG). This connection can be realized directly or indirectly via heat exchangers [31]. The number of connected households to the district heating grid for space heating is naturally limited up to $N$. To ensure space heating in each of the $N$ households and also assuming no redundancy, the equation

$$
n_{\mathrm{GB}, \mathrm{SH}}+n_{\mathrm{HP}, \mathrm{SH}}+n_{\mathrm{DHG}, \mathrm{SH}}+n_{\mathrm{FC}}=N
$$

is valid.

\subsubsection{Overview}

The household's quantities $n$ with different installed technical implementations are already defined as absolute values $0 \leq n \leq N$. To easier get an idea of the quotas of used technologies inside the whole area, ratios are defined. Coefficients $a$ to $g$ and $s, v, x, y, z$ describe the amount of households that use the corresponding device, compared to the total number of households inside of the considered residential area. Those ratios do not give any information about the installed capacity or maximum power output of the technology, they only serve as a guide to the technologies' distribution inside the district. Table 2 summarizes the considered various technologies and derived boundary conditions.

Table 2: Overview of the defined configuration coef-

\begin{tabular}{|c|c|c|c|}
\hline Technology & Coeff. & Def. & $\begin{array}{l}\text { Boundary } \\
\text { conditions }\end{array}$ \\
\hline PV & $a$ & $\frac{n_{\mathrm{PV}}}{N}$ & $0 \leq a \leq 1$ \\
\hline $\mathrm{FC}$ & $b$ & $\frac{n_{\mathrm{FC}}}{N}$ & $0 \leq \overline{\leq} \leq 1$ \\
\hline $\begin{array}{l}\text { El. grid } \\
\text { connection }\end{array}$ & $x$ & $\frac{n_{\mathrm{el}, \text { grid }}}{N}$ & $x=1$ \\
\hline $\begin{array}{l}\text { El. flow } \\
\text { heater }\end{array}$ & $c$ & $\frac{n_{\mathrm{FH}}}{N}$ & $\begin{array}{l}0 \leq c \leq 1, c= \\
1-b-d-e-y\end{array}$ \\
\hline $\begin{array}{l}\text { Heat pump } \\
\text { for hot water }\end{array}$ & $d$ & $\frac{n_{\mathrm{HPHW}}}{N}$ & $\begin{array}{l}0 \leq d \leq 1 \\
d=1-b-c- \\
e-y\end{array}$ \\
\hline $\begin{array}{l}\text { Gas boiler } \\
\text { for hot water }\end{array}$ & $e$ & $\frac{n_{\mathrm{GB}, \mathrm{HW}}}{N}$ & $\begin{array}{l}0 \leq e \leq 1 \\
e=1-b-c- \\
d-y\end{array}$ \\
\hline $\begin{array}{l}\text { Solar thermal } \\
\text { power }\end{array}$ & $s$ & $\frac{n_{\mathrm{ST}}}{N}$ & $0 \leq s \leq 1$ \\
\hline $\begin{array}{l}\text { DHG- } \\
\text { connection } \\
\text { for hot water }\end{array}$ & $y$ & $\frac{n_{\mathrm{DHG}, \mathrm{HW}}}{N}$ & $\begin{array}{l}0 \leq y \leq 1 \\
y=1-b-c- \\
d\end{array}$ \\
\hline $\begin{array}{l}\text { Heat pump } \\
\text { for space } \\
\text { heating }\end{array}$ & $f$ & $\frac{n_{\mathrm{HPSH}}}{N}$ & $\begin{array}{l}0 \leq f \leq 1, \\
f=1-b- \\
g-z\end{array}$ \\
\hline $\begin{array}{l}\text { Gas boiler for } \\
\text { space heating }\end{array}$ & $g$ & $\frac{n_{\mathrm{GB}, \mathrm{H}}}{N}$ & $\begin{array}{l}0 \leq g \leq 1, \\
g=1-b-f- \\
z\end{array}$ \\
\hline $\begin{array}{l}\text { DHG- } \\
\text { connection } \\
\text { for space } \\
\text { heating }\end{array}$ & $z$ & $\frac{n_{\mathrm{DHG}, \mathrm{SH}}}{N}$ & $\begin{array}{l}0 \leq z \leq 1 \\
z=1-b-f- \\
g\end{array}$ \\
\hline $\begin{array}{l}\text { Electric } \\
\text { vehicle }\end{array}$ & $v$ & $\frac{n_{\mathrm{EV}}}{N}$ & $0 \leq v$ \\
\hline
\end{tabular}
ficients of technical endowment.

\subsection{Configuration of final energy supply}

The possible configuration of technical implementation has been presented so far in section 3.2. Now, it is shown how to deal with the endowment in consideration of time-dependent consumer load in terms of electrical, tap water and space heating demand. 


\subsubsection{Supply of electric power $\boldsymbol{P}_{\mathrm{el}, \mathrm{FE}}$}

Here, the demand of pure electric power is divided into the two parts domestic basic service $P_{\mathrm{el}, \mathrm{FE}, \mathrm{dom}}(t)$ and EV charging power $P_{\mathrm{el}, \mathrm{EV}}(t)$ as mentioned in 3.2.1. To run electric devices or charge EV's batteries, the supply has to be forcefully electric. The net demand of the desired electric power $P_{\mathrm{el}, \mathrm{FE}, \mathrm{dom}}(t)$ as final energy can be derived from domestic standard load profiles as e.g in [32] and the demand for vehicle charging can be modeled e.g. on the basis of [33], as described below in section 4.2.1. The net demand $P_{\text {el,FE}}(t)$ for electric power can be met by PV or FC generation or has to be delivered via the external low voltage grid:

$$
P_{\mathrm{el}, \mathrm{FE}}(t)=P_{\mathrm{el}, \mathrm{FE}, \mathrm{dom}}(t)+P_{\mathrm{el}, \mathrm{EV}}(t)=\left\{\begin{array}{c}
P_{\mathrm{PV}}(t) \\
P_{\mathrm{FC}, \mathrm{el}}(t) \\
P_{\mathrm{el}, \mathrm{grid}}(t)
\end{array}\right.
$$

with

$$
\begin{gathered}
P_{\mathrm{PV}}(t)=\alpha(t) \cdot P_{\mathrm{el}, \mathrm{FE}}(t) \\
P_{\mathrm{FC}, \mathrm{el}}(t)=\beta_{1}(t) \cdot P_{\mathrm{el}, \mathrm{FE}}(t) \\
P_{\mathrm{el}, \text { grid }}(t)=\left(1-\alpha(t)-\beta_{1}(t)\right) \cdot P_{\mathrm{el}, \mathrm{FE}}(t)
\end{gathered}
$$

and the ratios $\alpha(t)>0$ and $\beta_{1}(t)>0$, giving what percentage of the electric final energy is delivered by the corresponding source at time $t$. If $\alpha(t)+\beta_{1}(t)$ becomes greater than 1 , excess electric power, generated by local PV panels and/or fuel cells, will be fed into the external electric grid.

PV generation In this model, energy from the sun is converted into electric power via PV cells. In reality, the usage of sun power is limited by the maximum possible size of the installed cells and the available roof top area for solar energy exploitation. In an initial approximation the roof top area of every house has the same size $A_{\mathrm{R}}$. The amount of electrical output depends on the direct solar radiation $i_{\text {dir }}[34]$ at time $t$ and on the usage ratio $\zeta_{\mathrm{PV}, i}$ which describes the part of used roof area compared to full roof area of household $i$.

The total generated power output by PV is given by

$$
P_{\mathrm{PV}}(t)=i_{\mathrm{dir}, \text { sun }}(t) \cdot \eta_{\mathrm{PV}} \cdot \sum_{i=1}^{n_{\mathrm{PV}}} A_{\mathrm{R}} \cdot \zeta_{\mathrm{PV}, i}
$$
cells

but limited to the maximum power output of the

$$
P_{\mathrm{PV}, \max }=\sum_{i=1}^{n_{\mathrm{PV}}} P_{\mathrm{nPV}} \cdot A_{\mathrm{R}} \cdot \zeta_{\mathrm{PV}, i}
$$

The advantage of electricity out of solar power is, that households can "share" the electric output via the low voltage network. As a result, the power $P_{\mathrm{PV}}(t)$ is either consumed completely within the district itself or can be fed into the overlayed grid structures. The temperature-dependency of PV cells shall be defined as

$$
\eta_{\mathrm{PV}}=\eta_{\mathrm{n}, \mathrm{PV}}+\tau_{\mathrm{PV}} \cdot T_{\mathrm{amb}}
$$

according to [34] with the normal efficiency $\eta_{\mathrm{n}, \mathrm{PV}}$ at $25{ }^{\circ} \mathrm{C}$ and the temperature coefficient $\tau_{\mathrm{PV}}<0$. That leads to a decrease in efficiency with higher ambient temperatures.

Fuel cell generation The total electrical output of all operating fuel cells at time $t$ is defined as

$$
P_{\mathrm{FC}, \mathrm{el}}(t)=\beta_{1}(t) \cdot P_{\mathrm{el}, \mathrm{FE}}(t)=\eta_{\mathrm{FC}, \mathrm{el}} \cdot \dot{E}_{\mathrm{NG}}(t)
$$

so the needed amount of natural gas can then be calculated by

$$
\dot{E}_{\mathrm{NG}}(t)=\frac{\beta_{1}(t)}{\eta_{\mathrm{FC}, \mathrm{el}}} \cdot P_{\mathrm{el}, \mathrm{FE}}(t)
$$

assuming all fuel cell systems have the same electric efficiency, $\eta_{\mathrm{FC}, \mathrm{el}}$, and the individual operation point, which has a direct influence on the coefficient $\beta_{1}(t)$, is known. The ratio $\psi_{\mathrm{FC}}$ of electrical compared to thermal output is defined as

$$
\psi_{\mathrm{FC}}=\frac{P_{\mathrm{FC}, \mathrm{el}}}{P_{\mathrm{th}, \mathrm{el}}} .
$$

The electrical and thermal generated power by fuel cells depends on its operating point which is not forcefully fixed. To simplify the operation algorithm within this method, it is assumed that the operation control of fuel cells is always heat guided and so the elecrical output of the FC can be determined by knowledge of the corresponding owners' heat demands which shall be satisfied by the fuel cell.

\subsubsection{Supply of hot water $\dot{Q}_{\mathrm{HW}, \mathrm{FE}}$}

The thermal power $\dot{Q}_{\mathrm{HW}}(t)$ for heating tap water can be provided in different ways. Only the already mentioned devices and implementations in section 3.2.2 (fuel cell, flow heater, heat pump, gas boiler, solar thermal panels and district heating grid connection) considered within this method.

The heat power for tap water can then be divided into the different parts:

$$
\dot{Q}_{\mathrm{HW}, \mathrm{FE}}(t)=\left\{\begin{array}{c}
\dot{Q}_{\mathrm{FC}, \mathrm{HW}}(t) \\
\dot{Q}_{\mathrm{FH}}(t) \\
\dot{Q}_{\mathrm{HP}, \mathrm{HW}}(t) \\
\dot{Q}_{\mathrm{GB}, \mathrm{HW}}(t) \\
\dot{Q}_{\mathrm{STS}}(t) \\
\dot{Q}_{\mathrm{DHG}, \mathrm{HW}}(t)
\end{array}\right.
$$


with

$$
\begin{gathered}
\dot{Q}_{\mathrm{FC}, \mathrm{HW}}(t)=\beta_{2}(t) \cdot \dot{Q}_{\mathrm{HW}, \mathrm{FE}}(t) \\
\dot{Q}_{\mathrm{FH}}(t)=\gamma(t) \cdot \dot{Q}_{\mathrm{HW}, \mathrm{FE}}(t) \\
\dot{Q}_{\mathrm{HP}, \mathrm{HW}}(t)=\delta(t) \cdot \dot{Q}_{\mathrm{HW}, \mathrm{FE}}(t) \\
\dot{Q}_{\mathrm{GB}, \mathrm{HW}}(t)=\epsilon(t) \cdot \dot{Q}_{\mathrm{HW}, \mathrm{FE}}(t) \\
\dot{Q}_{\mathrm{STS}}(t)=\sigma(t) \cdot \dot{Q}_{\mathrm{HW}, \mathrm{FE}}(t) \\
\dot{Q}_{\mathrm{DHG}, \mathrm{HW}}(t)=\left(1-\beta_{2}(t)-\gamma(t)-\delta(t)\right. \\
-\epsilon(t)-\sigma(t))(t) \cdot \dot{Q}_{\mathrm{HW}, \mathrm{FE}}(t)
\end{gathered}
$$

and the ratios $\gamma(t) \geq 0, \delta(t) \geq 0, \epsilon(t) \geq 0$ and $\sigma(t)$. The functionalities of power-to-heat via flow heaters and heat pumps have been already explained in section 2.4 and the heat supply by combustion of NG has been mentioned in 2.2. Hot water can neither be injected into an external grid nor shared between residencies, leading to the following condition being fulfilled at all times:

$$
1-\beta_{2}(t)-\gamma(t)-\delta(t)-\epsilon(t)-\sigma(t) \geq 0 .
$$

Solar thermal generation In this model, every household with installed solar thermal cells operates with the same type of cells, flat plate collectors. They are characterized by an improved heat insulation which leads to a vastly reduced loss of heat to the environment [35]. Here, a two-circle system is considered. The efficiency is defined by

$$
\eta_{\mathrm{ST}}=\frac{\dot{q}_{\mathrm{u}}}{i_{\text {glob }}}
$$

with usable specific heat $\dot{q}_{\mathrm{u}}$ and global radiation $i_{\text {glob }}$ under the estimation that both, direct and diffuse radiation, can be utilized. The efficiency's temperature-dependency is given by

$\eta_{\mathrm{ST}}=\eta_{\mathrm{o}}-\frac{1}{i_{\mathrm{glob}}} \cdot\left[k_{\mathrm{tot}}^{*} \cdot\left(T_{\mathrm{abs}}-T_{\mathrm{amb}}\right)+k_{1}\left(T_{\mathrm{abs}}-T_{\mathrm{amb}}\right)^{2}\right]$

with the term $\eta_{\mathrm{o}}$ representing the optical efficiency, the term $k_{\mathrm{tot}}^{*} \cdot\left(T_{\mathrm{abs}}-T_{\mathrm{amb}}\right)$ the convective and the term $k_{1}\left(T_{\mathrm{abs}}-T_{\mathrm{amb}}\right)^{2}$ the radiation losses. $T_{\mathrm{abs}}$ represents the absorber temperature [35].

Unfortunately, the produced heat by solar power of one household cannot be directly shared with other households. So, it is not possible to sum it all up, like for PV generation in equation 10. The produced heat, $\dot{Q}_{\mathrm{ST}, \mathrm{HW}, i}$, of the household $i$ with installed solar thermal cells with a ratio $\zeta_{\mathrm{ST}, i}$ of used roof area is

$$
\dot{Q}_{\mathrm{ST}, \mathrm{HW}, \mathrm{i}}(t)=i_{g l o b}(t) \cdot \eta_{\mathrm{ST}} \cdot A_{\mathrm{R}} \cdot \zeta_{\mathrm{ST}, i} .
$$

It has to be kept in consideration that PV and solar thermal cells are competing technologies in terms of covering the roof's area. In case that residences may have installed both technologies, it has to be ensured that the sum of the corresponding covering ratios $\zeta_{\mathrm{PV}, i}$ and $\zeta_{\mathrm{ST}, i}$ is not greater than 1 .

The use of solar thermal energy postulates the availability of a sensible hot water storage [35]. It is assumed that only the users of solar thermal powers run a water storage for tap water and all storages have a gas boiler as an additional conventional heat source connected to them. The not directly used solar thermal power can be added to the storage. For the detailed storage model see appendix 7. The term $\dot{Q}_{\mathrm{STS}}(t)$ represents a combined heat flow of the total solar thermal heat of the residential area and heat power by discharging the storages as in:

$$
\dot{Q}_{\mathrm{STS}}(t)=\dot{Q}_{\mathrm{ST}}(t)+\dot{Q}_{\text {storage }}(t) .
$$

district heating grid Households which are connected to the local district heating grid receive their hot water demand via a heat exchangers. Assuming negligible transition and heat exchange losses, the supplied power from the heating grid is given by

$$
\begin{aligned}
\dot{Q}_{\mathrm{DHG}, \mathrm{HW}}(t)= & \left(1-\beta_{2}(t)-\gamma(t)-\delta(t)\right. \\
& -\epsilon(t)-\sigma(t)) \cdot \dot{Q}_{\mathrm{HW}, \mathrm{FE}}(t) .
\end{aligned}
$$

\subsubsection{Supply of space heating $\dot{Q}_{\mathrm{SH}, \mathrm{FE}}$}

In section 3.2 .3 the regarded technical implementation for space heating, fuel cells, heat pumps, gas boiler and district heating, have been enumerated so far. Regarding these technologies, the total demand of space heating $\dot{Q}_{\mathrm{SH}, \mathrm{FE}}(t)$ at any time $t$ is covered by:

$$
\dot{Q}_{\mathrm{SH}, \mathrm{FE}}(t)=\left\{\begin{array}{c}
\dot{Q}_{\mathrm{FC}, \mathrm{SH}}(t) \\
\dot{Q}_{\mathrm{HP}, \mathrm{SH}}(t) \\
\dot{Q}_{\mathrm{GB}, \mathrm{SH}}(t) \\
\dot{Q}_{\mathrm{DHG}, \mathrm{SH}}(t)
\end{array}\right.
$$

with the heat supplies for the corresponding implementations:

$$
\begin{gathered}
\dot{Q}_{\mathrm{FC}, \mathrm{SH}}(t)=\beta_{3}(t) \cdot \dot{Q}_{\mathrm{SH}, \mathrm{FE}}(t) \\
\dot{Q}_{\mathrm{HP}}(t)=\varphi(t) \cdot \dot{Q}_{\mathrm{SH}, \mathrm{FE}}(t) \\
\dot{Q}_{\mathrm{GB}, \mathrm{SH}}(t)=\lambda(t) \cdot \dot{Q}_{\mathrm{SH}, \mathrm{FE}}(t) \\
\dot{Q}_{\mathrm{DHG}, \mathrm{SH}}(t)=\left(1-\beta_{3}(t)-\varphi(t)-\lambda(t)\right) \cdot \dot{Q}_{\mathrm{SH}, \mathrm{FE}}(t) .
\end{gathered}
$$

The ratio $\beta_{3} \geq 0$ represents the space heat generated by fuel cells, $\varphi(t) \geq 0$ the heating ratio of electric heat pumps and $\lambda \geq 0$ the part of space heating via gas boiler usage. Residual heating power has to be delivered by the district heating grid. 


\subsubsection{Overview}

Table 3 summarizes the coefficients and their dependencies on configuration, time, wheather and endowment.

Table 3: Overview over the dependencies of the varying coefficients.

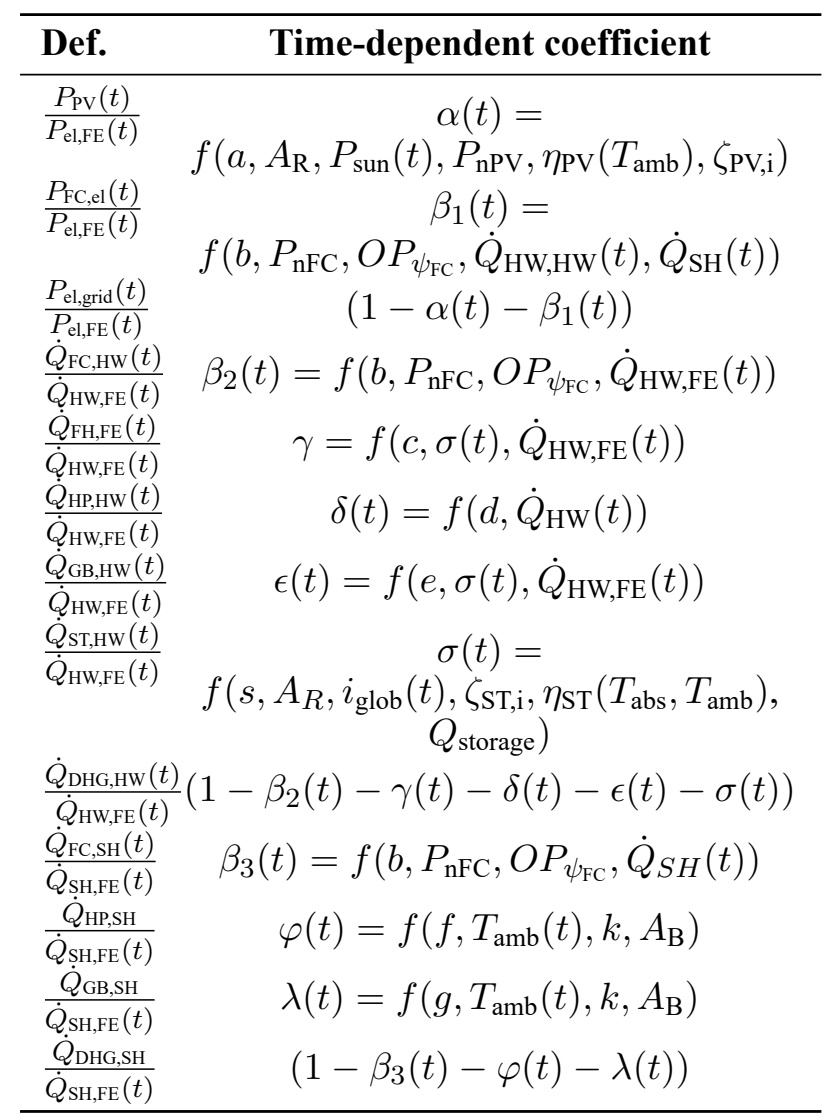

\subsection{Power delivery}

After the detailed explanation of the parts demand and supply of the final energy, in the following, the delivery side os focused. As already mentioned in section 2, the desired final energy can be delivered by various kinds of delivery energy and be made usable via power transformation of the end devices.

\subsubsection{Delivery of electric power}

The full power that has to be delivered in the form of electricity including the electric demand of heat pumps and flow heaters at every instant of time is

$$
\begin{gathered}
P_{\mathrm{el}, \mathrm{del}}(t)=P_{\mathrm{el}, \mathrm{grid}}(t)+P_{\mathrm{FH}}(t)+P_{\mathrm{HP}, \mathrm{HW}}(t)+P_{\mathrm{HP}, \mathrm{SH}}(t) \\
=\left(1-\alpha(t)-\beta_{1}(t)\right) \cdot P_{\mathrm{el}, \mathrm{FE}}(t)+\gamma(t) \cdot \frac{\dot{Q}_{\mathrm{HW}, \mathrm{FE}}(t)}{\eta_{\mathrm{FH}}} \\
+\delta(t) \cdot \frac{\dot{Q}_{\mathrm{HW}, \mathrm{FE}}(t)}{C O P_{\mathrm{HP}, \mathrm{HW}}}+\varphi(t) \cdot \frac{\dot{Q}_{\mathrm{SH}, \mathrm{FE}}(t)}{C O P_{\mathrm{HP}, \mathrm{SH}}} \\
=f\left(\alpha(t), \beta_{1}(t), \gamma(t), \delta(t), \varphi(t)\right) . \quad(26)
\end{gathered}
$$

The delivered electric energy $E_{\text {el,del }}$ for a fixed time period $T$ is then given by

$$
E_{\mathrm{el}, \mathrm{del}}=\int_{0}^{T} P_{\mathrm{el}, \mathrm{del}}(t) \mathrm{d} t .
$$

\subsubsection{Delivery of natural gas}

Natural gas has to be provided to cover its consumption in fuel cells, and gas boilers for water and space heating:

$$
\begin{gathered}
\dot{E}_{\mathrm{NG}, \mathrm{del}}(t)=\dot{E}_{\mathrm{FC}, \mathrm{NG}}(t)+\dot{E}_{\mathrm{GB}, \mathrm{HW}, \mathrm{NG}}(t) \\
\quad+\dot{E}_{\mathrm{GB}, \mathrm{SH}, \mathrm{NG}}(t) \\
=\beta_{1}(t) \cdot \frac{P_{\mathrm{el}, \mathrm{FE}}(t)}{\eta_{\mathrm{FC}, \mathrm{el}}}+\beta_{2}(t) \frac{\dot{Q}_{\mathrm{HW}, \mathrm{FE}}(t)}{\eta_{\mathrm{FC}, \mathrm{th}}}+\beta_{3}(t) \frac{\dot{Q}_{\mathrm{SH}, \mathrm{FE}}(t)}{\eta_{\mathrm{FC}, \mathrm{th}}} \\
+\epsilon(t) \cdot \frac{\dot{Q}_{\mathrm{HW}, \mathrm{FE}}(t)}{\eta_{\mathrm{GB}}}+\lambda(t) \cdot \frac{\dot{Q}_{\mathrm{SH}, \mathrm{EE}}(t)}{\eta_{\mathrm{GB}}} \\
=f\left(\beta_{1}(t), \beta_{2}(t), \beta_{3}(t), \epsilon(t), \lambda(t)\right) .
\end{gathered}
$$

The full energy delivery of natural gas is

$$
E_{\mathrm{NG}, \text { del }}=\int_{0}^{T} \dot{E}_{\mathrm{NG}}(t) \mathrm{d} t .
$$

\subsubsection{Delivery of district heating power}

The district grid is affected by the amount of households with a connection. The power that has to be delivered by the heating grid at any time $t$ is

$$
\begin{aligned}
& \dot{Q}_{\mathrm{DHG}, \mathrm{del}}(t)=\dot{Q}_{\mathrm{DHG}, \mathrm{HW}}(t)+\dot{Q}_{\mathrm{DHG}, \mathrm{SH}}(t) \\
= & \left(1-\beta_{2}(t)-\gamma(t)-\delta(t)-\epsilon(t)-\sigma(t)\right) \cdot \dot{Q}_{\mathrm{HW}, \mathrm{FE}}(t) \\
& \quad+\left(1-\beta_{3}(t)-\varphi(t)-\lambda(t)\right) \cdot \dot{Q}_{\mathrm{SH}, \mathrm{FE}}(t) \\
= & f\left(\beta_{2}(t), \beta_{3}(t), \gamma(t), \delta(t), \epsilon(t), \varphi(t), \lambda(t), \sigma(t)\right) .
\end{aligned}
$$

That leads to the heat $Q_{\mathrm{DHG}}$ to deliver in a time period $T$

$$
Q_{\mathrm{DHG}, \mathrm{del}}=\int_{0}^{T} \dot{Q}_{\mathrm{DHG}, \mathrm{del}}(t) \mathrm{d} t .
$$

\subsection{Operation algorithm}

Figure 3 depicts the algorithm's path for a time-period $T$ with calculation algorithm for every instant of time $t$ based on the known demand and a heat-controlled operation point of fuel cells. For ensuring the graphic's clarity, the storage model and EV charging algorithm model is not explicitely shown here. For detailed explanation of the EV charging algorithm see section 4.2.1, the storage model is described in the appendix. 


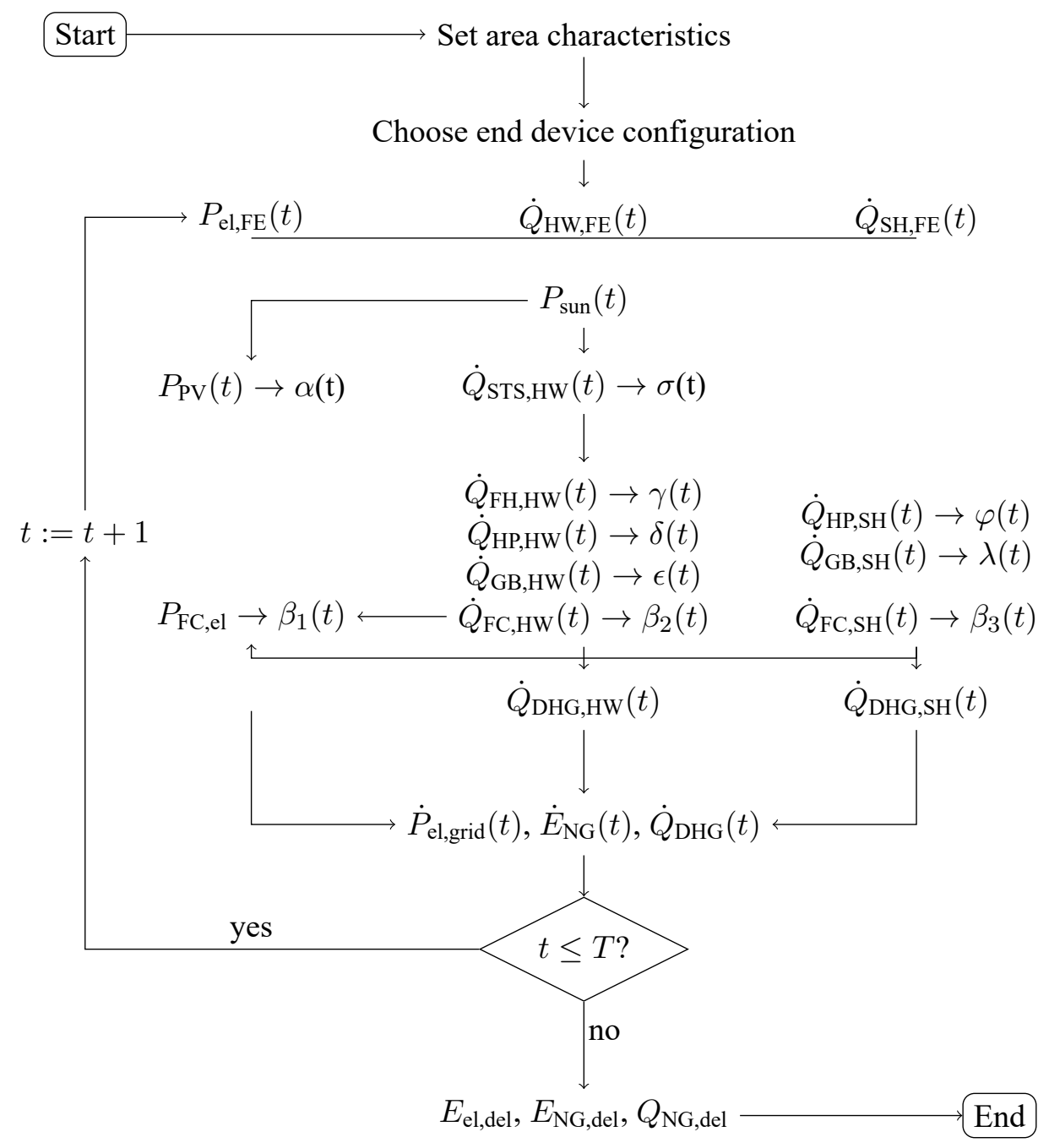

Fig. 3: Overview of the methodology's calulation algorithm.

At the very beginning, the basic parameters of the domestic areas, like number of households $N$, and building parameters have to be known from the development plan. Secondly, the composition of end devices for final energy supply has to be chosen, so that the coefficients $a, b, c, d, e, f, g, v$ have to be set in a way, that the boundary conditions, as mentioned in section 3.2, are fulfilled. The coefficients for ST, PV and the amount of the inhabitants' EV are also entered. The Latin coefficients are now fixed for the whole time period. Now the calculation is executed for every timestep $t$ to determine the time-dependent coefficients $\alpha, \beta_{1}, \beta_{2}, \beta, \gamma, \delta, \epsilon, \varphi$. At time step $t$, the electric final energy demands $P_{\mathrm{el}, \mathrm{FE}}(t)$, including basic service from standard load profiles and the electric charging power for EV, dependent on the daytime are calculated. The basic load is taken from knowledge of input data as exemplary in [32], the necessary EV power depends on the ratio $v$ for the amount of electric vehicles and the charging algorithm model as described in section 4.2.1. The demand of hot water $\dot{Q}_{\mathrm{HW}, \mathrm{FE}}(t)$ is calculated by the knowledge of demanded volume flow, according to empirical values as in [36] and knowledge of the temperature of delivered cold water and assumed desired temperature. The space heating $\dot{Q}_{\mathrm{SH}, \mathrm{FE}}(t)$ is mainly dependent on the ambient temperature and the building parameters and not regarding any unsteady heating processes. After the assignment of demand data, the power of sunlight $P_{\text {sun }}(t)$ is taken from meteorological data of radiation, as in [37]. By knowledge of $P_{\text {sun }}(t)$, the power of generated PV power can be calculated, regarding the efficiencies' temperature-dependency. The solar thermal power can be determined by equation 21 and the state of the corresponding storage is known from the previous timestep $t-1$. By knowledge of solar heat power $Q_{\mathrm{STS}, \mathrm{HW}(t)}$ the coefficient $\sigma(t)$ and the state of the storage for the next timestep can be calculated. Households without solar thermal and storage technology own one device which has to 
fulfill the heating demand for tap water. So the corresponding coefficients for flow heaters, gas boilers and heat pumps can be directly calculated out of the demand of tap water heating. Due to known space heating demand $\dot{Q}_{\mathrm{SH}, \mathrm{FE}}(t)$ the coefficients $\beta_{3}, \varphi$ and $\lambda$ can be calculated directly out of the heating demand. Fuel cells are assumed heat-leaded, so its generated electric power depends on the ratio $\psi_{\mathrm{FC}}$. So, the generated power by FC and the coefficient $\beta_{1}$ can then be calculated. By knowledge of the time-dependend coefficients in greek letters, the delivered power due to the corresponding energy sectors can be calculated by utilizing the equations 26,28 and 30 for every single time step. The delivery power can be integrated to determine amounts of energy for longer time periods. The main resources and input parameters which have to be given to the algorithm are

- The number $N$ of regarded households

- The coefficients $a, b, c, d, e, f, g, v$ that represent the distribution of the technical components and amount of EV inside of the whole area

- Demand data for single time steps (electric load profiles, tap water demand)

- Meteorological data as ambient temperature and solar radiation

- Building parameters as size, k-value and roof top area

- Efficiencies and their, if necessary, temperaturedependency for each kind of appliance

- Maximum output power of PV and solar thermal cells

- The ratio current to heat $\psi_{\mathrm{FC}}$ for fuel cells

- Assumptions as desired tap water temperature, room temperature, storage volume, water density

The methodology consists of the equations 1 - 31 within the manuscript and the equations 50-72. They are executed within the operation algorithm for every point of time $t$. The actual number of executed equations and so the computation time depends on the chosen versatility of end devices. The more varying end devices are taken into account the longer takes the computation time. For example, the storage model is quite complex in comparison to the quite straight algorithm and the state of the storage has always to be determined for the next time step. Also, the length of the chosen time period and the time resolution has an impact on the computation time, because the algorithm, as shown in figure 3 , is solved for every single point in time. The number of households $N$ does not affect the computation time because it just factorizes the data. Consisting of linear equations, the calculation algorithm is stable and fast. There is no iteration necessary. The computation time for executing the complete algorithm implemented in MATLAB ${ }^{\circledR}$ for a time period of 8760 time steps was observed to be around 80 seconds.

\section{Execution of the method}

So far, the method and its working algorithm have been presented generally. Now, the methodology is executed for exemplary configuration scenarios with different appliance distributions within an exemplary residential area of $N=100$ households for a time period of $T=8760 \mathrm{~h}$. The algorithm is programmed and the calculation is done in MATLAB ${ }^{\circledR}$.

\subsection{Configuration scenarios}

Nevertheless, the methodology is able to deal with various configuration approaches, to get to some general conclusions for future grid expansion strategies, some extreme scenarios shall be considered so far. The main scenarios shall be

- S1 a) All electric

- S1 b) All el. \& PV

- S2 a) Gas, conventional

- S2 b) Gas \& fuel cell

- S2 c) Gas \& solar thermal

- S3 District heating

to compare three very different grid expansion strategies. Scenarios 1 and 2 are also supplemented by different kinds of devices and to evaluate the renewable potential of PV power and solar thermal power scenarios in S1 a) and S2 c). The amount of EV is constantly chosen as $v=0.5$ within the different scenarios here. The impact of the number of $\mathrm{EV}$ on the whole electric power demand in the system is shortly sdiscussed in 5.1. Table 4 gives an overview over the chosen endowment coefficients for the defined scnearios. Further parameters and assumptions for device values and building characteristics are mentioned in the appendix.

\subsection{Final energy demands}

To execute the methodology, the final energy demands of the considered residential area have to serve as input values, so the methodolgy itself depends on the quality of forecasted demand data. The demands are predetermined by the consumers' behavior and ambient boundary conditions. In the following, the data base on the assumed demands of final energy is 
Table 4: Scenario definitions for different technical configurations for the domestic final energy supply.

\begin{tabular}{cccccccc}
\hline Device & Coeff & $\begin{array}{c}\text { S1 a) } \\
\text { All el. }\end{array}$ & $\begin{array}{c}\text { S1 b) } \\
\text { All el. \& PV }\end{array}$ & $\begin{array}{c}\text { S2 a) } \\
\text { GB, conv. }\end{array}$ & $\begin{array}{c}\text { S2 b) } \\
\text { GB \& FC }\end{array}$ & $\begin{array}{c}\text { S2 c) } \\
\text { GB \& ST }\end{array}$ & $\begin{array}{c}\text { S3 } \\
\text { All DHG }\end{array}$ \\
\hline PV & $a$ & 0 & 0.2 & 0 & 0 & 0 & 0 \\
FC & $b$ & 0 & 0 & 0 & 0.2 & 0 & 0 \\
FH & $c$ & 0.5 & 0.5 & 0 & 0 & 0 & 0 \\
El. Grid & $x$ & 1 & 1 & 1 & 1 & 1 & 1 \\
HP, HW & $d$ & 0.5 & 0.5 & 0 & 0 & 0 & 0 \\
GB, HW & $e$ & 0 & 0 & 1 & 0.8 & 1 & 0 \\
ST & $s$ & 0 & 0 & 0 & 0 & 1 & 0 \\
DHG, HW & $y$ & 0 & 0 & 0 & 0 & 0 & 1 \\
HP, SH & $f$ & 1 & 1 & 0 & 0 & 0 & 0 \\
GB, SH & $g$ & 0 & 0 & 1 & 0.8 & 1 & 0 \\
DHG, SH & $z$ & 0 & 0 & 0 & 0 & 0 & 1 \\
EV & $v$ & 0.5 & 0.5 & 0.5 & 0.5 & 0.5 & 0.5 \\
\hline
\end{tabular}

briefly presented. The resulting demands of electric power, tap water and space heating for the exemplary desitrict are shown in 12

\subsubsection{Electric demand}

The demand for electric power is devided in the two main parts basic domestic load and EV charging.

Electric basic load The demand curves for domestic pure electrical basic load $P_{\mathrm{el}, \mathrm{FE} \text {,dom }}$ is given for the whole district and developed from standard load profiles, as in [32]. Taking standard load profiles into account, it has to be kept in consideration, that only the basic load has to put in as a demand here and not additionally involving heat pump, flow heater or EV charging power, because they are considered elsewhere within this calculation. Because the low voltage grid is ascribed ideal behaviour and the inhabitants of the residential area are able to share and exchange electrical power, the load profile for the whole district is simplifying assumed to be the product of load profiles as in [32] times factor $N$. The improvement of forecasting demand data shall not be part of this manuscript. For further research focusing on bottom-up strategies for domestic load profiles see e.g. [38].

EV charging The load $P_{\text {el,EV }}$, caused by charging electric vehicles, is determined after a model based on study [33]. To identify the energy consumption of EVs, some assumptions are made for energy consumption per $\mathrm{km}, e_{\mathrm{EV}}$, and average driving routes, $l_{\mathrm{EV}}$, per vehicle and day are made. Hence, the amount of energy, $E_{\mathrm{EV}, \text { charge, }}$ for a complete charging process of one vehicle can be calculated. The energy demand of $15 \%$ of EV-owners is assumed uniformly distributed to the daily time span 6 am to $4 \mathrm{pm}$. The majority of the car drivers (70\%) is assumed to charge their vehicles with a constant load $P_{\mathrm{EV} \text {,charge, starting }}$ the process of charging by equably arriving at home from $4 \mathrm{pm}$ to $8 \mathrm{pm}$ arriving. The residual $15 \%$ is assumed as public charging and not considered under the premise that the residential area itself does not own public charging stations and so the residual charging is executed off site. Additionally, for charging batteries the AC supply has to be rectified to DC and an efficiency $\eta_{\mathrm{EV} \text {,charge }}$ might be considered. The electric power supply for the time period from $6 \mathrm{am}$ to $4 \mathrm{pm}$ can then be calculated by the equation

$$
\begin{aligned}
P_{\mathrm{el}, \mathrm{EV}}(t)=0.15 \cdot n_{\mathrm{EV}} \cdot \frac{E_{\mathrm{EV}, \text { charge }}}{10 \mathrm{~h}} \cdot \frac{1}{\eta_{\mathrm{EV}, \text { charge }}} \\
\forall 6 \mathrm{am} \leq t<4 \mathrm{pm} .
\end{aligned}
$$

For the charging process in the evening with assumed constant charge load $P_{\mathrm{EV} \text {,charge, }}$, the duration for full charging for every verhicle can be calculated by

$$
t_{\mathrm{EV}, \text { charge }}=\frac{E_{\mathrm{EV}, \text { charge }}}{P_{\mathrm{EV}, \text { charge }}} .
$$

The charging power of every group of vehicles returning home and starting charging at $t_{0}$, assuming uniformly returning vehicles between $4 \mathrm{pm}$ and $8 \mathrm{pm}$ until point of time $t_{0}+\left\lfloor t_{\mathrm{EV} \text {,charge }}\right\rfloor$ is given by

$$
P_{\mathrm{el}, \mathrm{EV}}\left(t_{0}+t\right)=P_{\mathrm{EV}, \text { charge }} \forall t \leq\left\lfloor t_{\mathrm{EV}, \text { charge }}\right\rfloor .
$$

The remaining necessary charging power is shaved constantly over the full following timestep $t_{0}+\left\lceil t_{\text {charge }}\right\rceil$ 


$$
\begin{aligned}
& P\left(t_{0}+\left\lceil t_{\text {charge }}\right\rceil\right)= \\
& \frac{0.7}{5} \cdot n_{\mathrm{EV}} \frac{1}{1 \mathrm{~h}} \cdot\left(E_{\mathrm{EV}, \text { charge }}\right. \\
& \left.-\int_{t_{0}}^{\left\lfloor t_{\mathrm{EV}, \text { charge }}\right\rfloor} P_{\mathrm{EV}, \text { charge }} \mathrm{d} t\right) \\
& \cdot \frac{1}{\eta_{\mathrm{EV}, \text { charge }}}
\end{aligned}
$$

The demand for the EV-models depends on the assumed connection power, battery capacity and assumed average route distance, which can be easily modified at the methodology's setting at the beginning. The charging load as a variable can be easily adapted to different battery models due to developing trends of EV manufacturers' market penetration. Additionally, the functionality of the method itself is totally independent by the input data model of EV charging processes, because it only affects the electric final energy demand $P_{\mathrm{el}, \mathrm{FE}}(t)$. Hence, it is possible to utilize different charging algorithms in combination with the method's execution.

For the chosen EV parameters of the exemplary execution see table 6 .

\subsubsection{Hot water demand}

For the tap water's demand, literature and empirical values as in[36] (see figure 10) can be used. In [36] percentiles that are used during the day for one household are given. The more residences are involved, the better the curve fits [36]. A usage of $35 \mathrm{~L}$ per person and day at a desired water temperature of $45^{\circ} \mathrm{C}$ is assumed in this model. The demand of hot water as final energy is then given by

$$
\dot{Q}_{\mathrm{HW}, \mathrm{FE}}=\dot{V}_{\mathrm{HW}} \cdot \rho_{\mathrm{water}} \cdot c_{p, \text { water }} \cdot\left(T_{\mathrm{HW}}-T_{\mathrm{del}}\right) .
$$

To modify it to the hourly consideration, it can be transferred to the integrated volume flow for one hour with an assumed constant density of $\rho_{\text {water }}=0.997 \frac{\mathrm{kg}}{\mathrm{m}^{3}}$, the desired temperature $T_{\mathrm{HW}}$ and the temperature of delivered fresh water $T_{\text {del }}$. The difference in total hot water usage between weekend and weekdays is neglected. It is trivial, that in reality the usage of warm water is not synchronous. But because of simplicity, it is assumed that the distribution of use for warm water supply (solar thermal, flow heater, NG boiler and district heating grid) of that percentage correspond to the total distribution of the different devices. The appearing inaccuracy for single time steps should be compensated by long term calculations and by the high number of considered households. Also, the efficiencies of single devices are assumed independent from their load.

\subsubsection{Space heating demand}

Since the demand for space heating directly depends on the season, more precisely on the ambient temperature, that demand will arise in the whole domestic sector more or less at the same time. On the premise of similar building structures and parameters, especially regarding the footprints $A_{\mathrm{B}}$ and insulation properties, the heat demand of every individual building is assumed equal.

According to [30], the stationary heat loss through the outer walls of buildings is devided into the main two parts transmission losses $\dot{Q}_{\text {transm. }}$ defined by

$$
\dot{Q}_{\text {transm. }}=k_{\text {tot }} \cdot A_{\mathrm{B}}\left(T_{\mathrm{in}}-T_{\mathrm{amb}}\right)
$$

and the ventilation losses

$$
\dot{Q}_{\text {vent. }}=\dot{V}_{\text {air }} \cdot \rho_{\text {air }} \cdot c_{p, \text { air }} \cdot\left(T_{\text {in }}-T_{\text {amb }}\right)
$$

The $k_{\text {tot }}$-value (coefficient of heat exchange) for the transmission loss $\dot{Q}_{\text {transm. }}$ is dependent on the wall material, insulation and the number and structure/design of windows and the roof [30]. The heat exchange with the earth is considered in an equal manner to the heat exchange with the environment which leads to an overestimation of the convective heat losses.

To calculate the ventilation losses, the ratio of air exchange $n_{\text {air,exch. }}$ and the volume $V_{\mathrm{B}}$ of the whole building has to be assumed empirically.

Decreasing the space heating load by usage of solar radiation as "indirect solar thermal use" [35] is not taken into account here.

\section{Results}

In the following the results for the exemplary scenarios from table 4 shall be presented and discussed.

\subsection{Influence of personal EV charging on electric power demand}

The introduced EV charging model, as described in section 3.3.1, varies a lot from the conventional load profile for electric basic load. The difference in necessary electric power demand of EV, $P_{\mathrm{el}, \mathrm{FE}, \mathrm{EV}}$ is exemplary shown for different amount of EVs, represented by defined share of $v=0.1, v=0.5, v=0.75$ and $v=1.0$ in comparison to the constant electric basic load $P_{\text {el,FE,dom }}$ in figure 4 .

Discussion By using the approach of [33] to define EV charging processes and assuming different $\mathrm{EV}$ shares up to $v=1.0$ (every household owns one in average) the big impact of uncontrolled private charging for the necessary electric power delivery becomes obvious as pictured in figure 4. Also, the peak during 


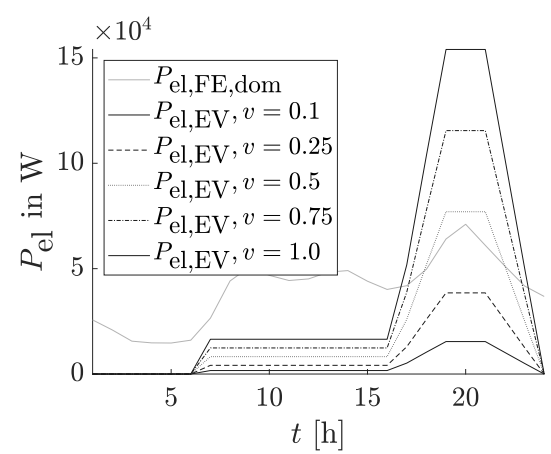

Fig. 4: Electric power demand for domestic use, according to [32], and EV charging for different amounts of EV, modeled according to [33] for $N=$ 100 households.

the end of working day in the late afternoon is increasing dramatically, according to the assumed charging behavior.

By regarding the effect of a growing amount of EV in society, the EV industry itself now affects the wired electricity energy sector and, using sector-coupling, possibly also the gas grid, unlike former times with only combustion engines in the transportation sector. By using the method with varying coefficients $v$, the effect of EV penetration for the load flow gets obvious and conclusions can be drawn out of the results also by EV industry. In terms of avoiding repowering of line capacities, battery manufacturers and charging station providers could provide grid-assistive charging processes by smart-metering for EV to shave load peaks. For private charging stations such algorithms are developed in [39] and for big bus stations in [40]. But unlike former connection capacities and grid expansion approaches for only domestic supply in the low voltage level, growing amounts of EV and the resulting increasing electric demand for residential areas have to be considered precociously for future planning processes.

\subsection{Power delivery}

At this point the calculation's results for the delivered power of the three supply sectors are shown. The following figures 5,6 and 7 picture the necessary power delivery of the three energy carriers according to the defined configuration scenarios in table 4 and the equal input of final energy demand data given in figure 12 in the appendix.

Discussion Obviously the different configuration of end devices affect the amount of delivery power in all three energy sectors. Providing heat electrical as in scenario S1 a) doubles the necessary electric power compared to the DHG-scenario S3 during winter at the peak load. That has to be considered for the

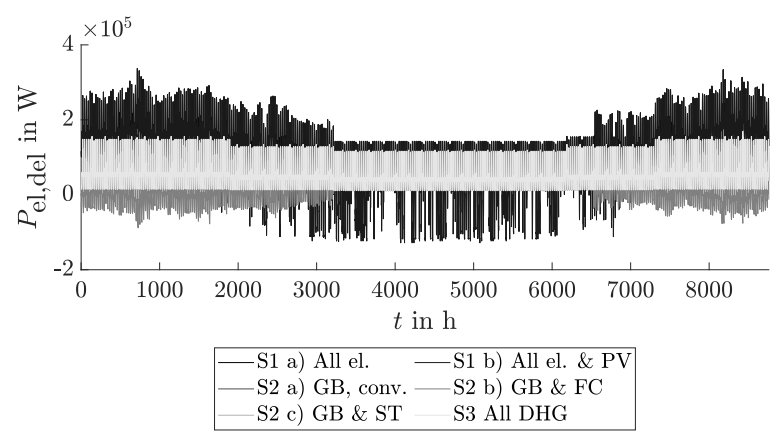

Fig. 5: Electric power delivery for all configuration scenarios.

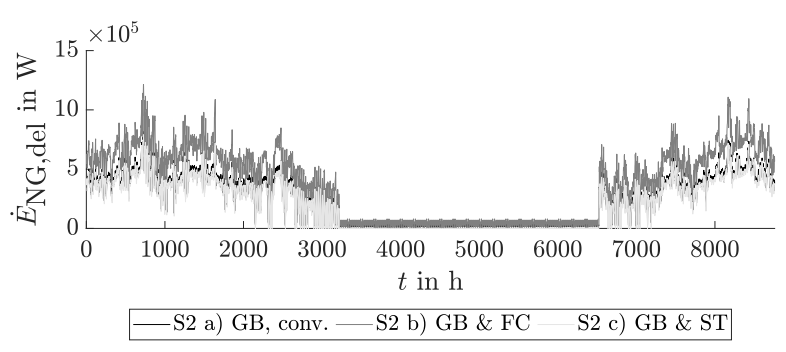

Fig. 6: Delivery of natural gas for the different configuration scenarios S2 a), S2 b) and S2 c).

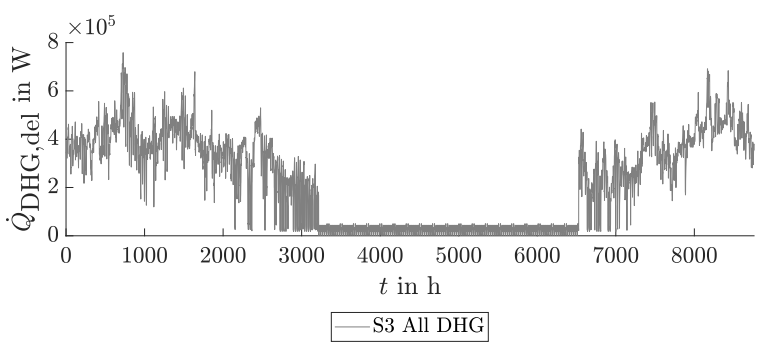

Fig. 7: Delivery of district heating heat for the configuration scenario $\mathrm{S} 3$.

design of line capacities. In this investigation only space heating is involved but by also taking electric space cooling during summer into account, the delivery of electric power would increase also during the summer season. Furthermore, the transmission and distribution capacities for ensuring heating and cooling power cannot be reduced using simultaneity factors, as it is usual in established electrical grid planning strategies to estimate occuring peak loads [27], because it affects the whole location at the same time, unlike conventional electrical devices in the low voltage area. Hence, established standard load profiles for the domestic sector are no longer valid 
to draw conclusions for the actual load flow with an existing high share of electrical heating and cooling. Assuming high share of installed PV-power, as in S1 b), it is visible that a high amount of electric power is fed back to the grid especially during summer, due to the high amount of direct radiation at noontime. High share of PV-generation could endanger partially overloading of grid structures due to the local simultaneity of radiation. Batteries to store the excess power at home for own power consumption are not considered so far but could serve as a grid-assistive benefit, so including private storages could be an add-on to the so far presented methodology and will be part of further development of the methodology. Also, combining own PV-generation with heat pump cooling processes during summer is a conceivable approach.

Unlike the PV-scenario S1 b), the FC-scenario S2 b) causes electrical feed into the grid during winter months, resulting from the presupposed heat guided operating points of FC. With a high local share of FC heating systems, the same issues as caused by PV generation appear. Including private battery storages for FC systems could also be a strategy to release the electric grid in that case.

Looking at the results for the gas delivery in figure 6, it gets obvious that especially the gas sector is affected by the demand of space heating and tap water heating in the gas scenarios S $2 \mathrm{a}$ ), b), and c). The necessary amount of delivered gas power can be slightly reduced by private using ST and storage-systems to support tap water heating, comparing the scenarios S2 a) and S2 c). The higher demand of natural gas within the FC scenario S2 b) compared to the conventional GB-scenario S2 a) occures due to the lower thermal efficiency of FCs unlike the high thermal efficiency of GBs. As already mentioned above, involving battery storages for FC-produced electricity inside this methodology would pose a significant benefit, justifying the higher gas consumption by not feeding into electric grid structures as seen in figure 5 for scenario $\mathrm{S} 2 \mathrm{~b}$ ). With even further growing share of private FC technology, the gas demand itself would maybe outstrip existing transmission or connection capacities which have been designed for conventional boilers.

Within the defined scenarios, the district heating grid is only considered in scenario S3 to provide the full heat for space and tap water. In scenario S3 the delivery of electric power only consists of fulfilling pure electrical demand like for basic appliances and EV charging and so it is not operating with high load flow compared to the other scenarios, especially the "All electric" S 1a) and S 1b). The gas grid itself does not have to be build in that case, so only the electric and district heating grids are affected.
By using the presented method as a "green meadow" approach for totally new built development areas, it is obvious, that by setting the end devices of the domestic consumers in an appropiate way, whether the power has to be supplied only electrical (S1 a) and b)), electrical and NG (S2 a), b) and c)) or electrical and DHG (S3) or even by all three sectors, regarding quite unfavorable configurations. But the opportunity to try out various appliance configurations using the presented methodology for development areas leads to conclusions for the necessary power supply of the different sectors. The configuration can also be suitably designed for nearby existing grid structures to avoid an unnecessary complex expansion of more distant structures. So the degree of freedom in the design of consumer's technical endowment can be taken into account for future grid expansion strategies to ensure grid-assistive power supply for every of the three sectors. But also regarding an already existing residential area with connected grid structures of known capacities: By extention of the municipality, the reliable power supply for the existing and the new buildings has to be ensured. So, the final energy supply of newly built buildings could be realized grid-assistive, by smart installing of the appropriate end device, utilizing free capacities of one energy carrier by not affecting capacities of others which might be working at their limits.

Hence, in terms of grid expansion the power delivery of consumer sectors has to be considered in a holistic way. Various kinds of power transformation and the resulting possibilities for satisfying final energy demand in the domestic sector have a direct impact on the delivered power as seen in the figures 5, 6 and 7. So the holistic consumer design itself increases the flexibility of the system and should be incorporated as a parameter of high degree of freedom for future integrated expansion strategies. The technical design of one single household does not strongly affect on the whole system but the overall composition of large consumer structures directly affects the amount of delivery power and therefore the necessary line and pipeline capacities. Considering the following example: For one consumer in an already established residential area it could be advantageous providing space heat electrical due to personal reasons but if the whole district comes up to this idea, the electric grid, maybe built in former times according to obsolete strategies, and also assuming growing number of $\mathrm{EV}$, the electric capacities could get to its limits and expansive and complex expansion procedures have to be executed. To avoid that case, the way of providing space heating can be distributed smartly to free infrastructures of other energy carriers like gas and heat. That example is only one reason to 
picture, why an holistic and multi-modal approach is so important, not only for the grids itself, but also including consumer structures. That is why the presented methodology is developed to include all of the three energy sectors and works with distribution factors of various end devices for whole residential areas.

\section{Rating Criteria}

To rate a full energy systems there are several options and criteria existing, as already mentioned in section 1. The relative criteria can be chosen based on subjective interests and opinions. The so far introduced methodology can be used to try out different configurations of appliances in domestic power supply and compare them directly to each other in terms of selected aspects. Some possible rating values and the corresponding objective functions shall be introduced here to serve as a base for further investigations on objective or multiobjective optimization of the method.

\subsection{Primary energy input}

One criterion to evaluate the best configuration could be the primary energy input to meet the demands of final energy consumption inside the considered domestic sector. The primary energy consumption is defined by the equation

$$
E_{\text {prim }}=E_{\mathrm{FE}} \cdot p_{\mathrm{f}} .
$$

The primary energy factors $p_{\mathrm{f}}$ varies by the total configuration of generators in the grid. The value of the objective function at every time shall be defined as

$$
f(t)=p_{\mathrm{f}, \mathrm{el}} P_{\mathrm{el}}(t)+p_{\mathrm{f}, \mathrm{NG}} \dot{E}_{\mathrm{NG}}(t)+p_{\mathrm{f}, \mathrm{DHG}} \dot{Q}_{\mathrm{DHG}}(t) .
$$

But only if the condition

$$
P_{\mathrm{el}}(t)>0,
$$

is valid, which represents power flow from grid to consumer, it is included inside the objective function $f(t)$.

Otherwise, if

$$
P_{\text {el }}(t)<0
$$

is valid at time $t$ and the inhabitants of the residential area generate too much electric power (by PV or FC) to just satisfy their own consumption, they have to feed it back into the grid. Because there is no "profit" for primary energy - renewable power has a primary energy factor of 0 - and the used gas for running a fuel cell is already included in the NGconsumption, that surplus is not considered in equation 40. Therefore, the term $p_{\mathrm{f}, \mathrm{el}} P_{\mathrm{el}}(t)$ cannot become smaller than 0 . The total objective function as the summation over time for a longer time period

$$
F=\int_{0}^{T} f(t) \mathrm{d} t
$$

can be a criterion for rating the primary energy quality of the regarded area.

\subsection{Transformation efficiency}

By using various kinds of appliances for domestic power supply, several options for power transformation have been depicted so far. Power transformation is always liable to transformation losses and the smaller the losses, the higher the efficiency. A value $\eta_{\text {del }}$ is defined to characterize the time-dependent transformation efficiency of the considered system, given as

$$
\begin{aligned}
\eta_{\mathrm{del}}(t) & =\frac{\dot{E}_{\mathrm{FE}}(t)}{\dot{E}_{\mathrm{del}}(t)} \\
= & \frac{P_{\mathrm{el}, \mathrm{FE}}(t)+\dot{Q}_{\mathrm{SH}}(t)+\dot{Q}_{\mathrm{HW}}(t)}{P_{\mathrm{el}, \mathrm{del}(t)}+\dot{E}_{\mathrm{NG}, \mathrm{del}}(t)+\dot{Q}_{\mathrm{DHG}, \mathrm{del}}(t)}
\end{aligned}
$$

It only represents the ratio of power output to input, not factoring or rating the worthiness of the energy carriers. The average efficiency $\eta_{\text {del }}$ for a desired period of time shall be defined as the quota of the summed energy output to input, as in

$$
\bar{\eta}_{\mathrm{del}}=\frac{E_{\mathrm{FE}}}{E_{\mathrm{del}}}=\frac{E_{\mathrm{el}, \mathrm{FE}}+Q_{\mathrm{SH}}+Q_{\mathrm{HW}}}{E_{\mathrm{el}, \mathrm{del}}+E_{\mathrm{NG}, \mathrm{del}}+E_{\mathrm{DHG}, \mathrm{del}}} .
$$

\subsection{Transmission efficiency}

Not only transformation, but also transmission losses inside the system and in overleyed grid structures occure via power transformation and can be taken into account for evaluation. Introducing the time-variable necessary power input $\dot{E}_{\text {in,sys }}(t)$ respectively energy input $E_{\text {in,sys }}$ for a time period, efficiency values can be defined as

$$
\eta_{\text {transm. }}(t)=\frac{P_{\mathrm{el}, \mathrm{del}}(t)+\dot{E}_{\mathrm{NG}, \mathrm{del}}(t)+\dot{Q}_{\mathrm{DHG}, \mathrm{del}}(t)}{\dot{E}_{\mathrm{in}, \mathrm{sys}}(t)}
$$

as time-dependent efficiency and

$$
\bar{\eta}_{\text {transm. }}=\frac{E_{\text {del, RA }}}{E_{\text {in,sys }}}
$$

as the average transmission efficiency for a longer time period. The transmission losses, of course, and so the input power, resp. energy, highly depent on the defined system boundaries.

Active power losses especially refer to ohmic losses 
along electric transmission lines, which directly depend on the load flow, specific restistance of the line material and the length of transmission lines. Small transformer losses have to be taken into account by regarding different voltage-levels. Transmission losses in electric three-phase AC grids can be determined via iterative load flow calculation methods like e.g. Newton-Raphson [27] or approximately estimated using DC load flow calculation [41].

Pressure losses along gas pipelines emerge of gas friction between moving molecules and the inner pipeline wall so they mainly depend on the pipe's geometric structure like roughness, diameter and length, to the flow velocity flow to the power of two (turbulent flow) and the gas characteristics like e.g. the density or velocity as temperature-dependent values [42].

Heat losses in the heating grid mainly depend on the pipe length, the temperature difference between the process fluid and ambient temperature and the heattransfercoefficient of the pipeline material.

\subsection{Capital expenditure for grid expansion}

Grid expansion is not only a technical challenge, but also economic aspects play a role in expansion strategies. The building price of line and pipe infrastructure directly depends on the form of energy, the transfer capacity, which results from the maximum power transfer of electric lines [27] or gas/heat pipes and the transmission distance. With the specific costs per $\mathrm{km}$ transmission line $c_{\text {capex }}$ for the corresponding energy carrier and the necessary length of the relative transmission lines, dependent on the location of existing overleyed structure, the capital expenditure can be calculated as

$$
\begin{aligned}
C_{\text {capex }}= & c_{\text {capex,el }} \cdot l_{\text {transm.,el }} \cdot P_{\text {el,max }} \\
& +c_{\text {capex }, \mathrm{NG}} \cdot l_{\text {transm.,NG }} \cdot \dot{E}_{\mathrm{NG}, \max } \\
& +c_{\text {capex }, \mathrm{DHG}} \cdot l_{\text {transm.,DHG }} \cdot \dot{Q}_{\mathrm{DHG}, \max } .
\end{aligned}
$$

With the presented method, the amounts of maximum delivery power of the three energy sectors can be approximately forecasted for residential areas, of course dependent on the approache's technical endowment for final energy supply and also on the quality of demand and climate data. With the knowledge of necessary delivery power of the different energy carriers and the resulting investment costs, future transmission structures can be performed foresightedly and integratedly, including all the three sectors, with higher economically effectiveness.

\subsection{Energy production costs}

The production costs of the energy carriers electricity, gas and heat differ greatly from each other. Especially the electricity's production costs highly depend on the kind of generation technology, e.g. nuclear, fossil or renewable generation. Also the way of generating district heat, wheather with CHP or heating plants, plays a role for the production cost of heat. The pricing for NG is dependent on the exploitation of gas sources and global political impacts. Hence, the total power production costs of investigated residential areas depend on the specific production costs and the amounts of relative energy carrier to deliver, already regarding the transmission losses, mentioned in section 6.3 can be determined by

$$
\begin{array}{r}
C_{\text {opex }}=c_{\mathrm{PC}, \mathrm{el}} \cdot \int_{0}^{T} \frac{1}{\eta_{\mathrm{el}, \text { transm. }}(t)} P_{\mathrm{el}, \mathrm{del}}(t) \mathrm{d} t \\
+c_{\mathrm{PC}, \mathrm{NG}} \cdot \int_{0}^{T} \frac{1}{\eta_{\mathrm{NG}, \text { transm. }}(t)} \dot{E}_{\mathrm{NG}, \mathrm{del}}(t) \mathrm{d} t \\
+c_{\mathrm{PC}, \mathrm{DHG}} \cdot \int_{0}^{T} \frac{1}{\eta_{\mathrm{DHG}, \text { transm. }}(t)} \dot{E}_{\mathrm{DHG}, \mathrm{del}}(t) \mathrm{d} t .
\end{array}
$$

\subsection{Resident's investment and operation costs}

So far, the presented method is constructed in a way so that the distribution of technical implementations inside of the residential area is specified at the beginning. If an advantagous composition of endowment in the area results e.g. from the above mentioned criteria, individual inhabitants or possible owners of the buildings would not have any opportunity for co-decision in fulfilling their demand of final energy. In reality, the owner is free in the arrangement of his domestic energy supply, satisfying the technical connecting conditions of the network operators presupposed. Resident's personal interests can differ a lot from national economical or ecological ones. One main design factor of domestic endowment could be the investment costs for grid connection or installation of the different devices like PV, storage, flow heater, gas boiler et cetera, another one the pricing of the delivered energy carrier: Though Electricity is the most precious and flexible form of power, it is quite expansive, compared to the more convenient NG or heat. A personal economic and ecological analysis requires the knowledge of personal living conditions and consumer habits. For the reason that this method is mainly constructed for the provider's point of view so far, personal optimization strategies for single households should not be pictured here.

\section{Conclusions and further research}

In terms of increasing renewable power generation and high electrification of the transportation sector, existing electric grid capacities may get overloaded. To face this challenge, not only expanding electrical infrastructure, but increasing a system's flexibility 
and storage ability by incorporating other transmission and storing structures, like the gas grid, as a so called "integrated grid expansion", may be one sustainable approach to successfully accomplish the energy transition. As a contribution to estimate the potential of integrated grid structures, a methodology referring to the domestic sector, utilizing the high technical flexibility of final energy supply, has been developed and explained within the manuscript. It has been executed for six exemplary configuration scenarios and the power demand for EV charging and the necessary delivery power of the three energy sectors electricity, gas and heat, have been presented and discussed in section 5. As a result, a new holistic methodology has been developed which

- is versatile by including various kinds of end devices

- offers nearly infinite selection of technical configuration distributions

- is universally and feasibly transferable to residential areas of different size and configuration

- can be combined with different demand forecasting methods and EV charging models

- is adaptable for special interests and needs by small modifications

- is easily extendable by adding further technologies

- generates fast impression of necessary power delivery for plenty distributions of end devices

- can serve as a basis for comparison of various configuration according to differing objectives

- is stable and fast due to its linear characteristic

Additional to those advantages, the methodology offers multifunctional applicability. The declared objectives, concerning primary energy input, system efficiency and investment or operation costs, address several target audiences, taking differing priorities and subjective interests into account. They serve as a basis for comparison and evaluation between various configuration designs and to draw conclusions regarding grid expansion strategies by concerning and weighting different rating criteria.

Presupposed the realistic character of the input final energy demand data, the execution of several configuration scenarios, as already elaborately shown and discussed in chapter 5, leads to the following conclusions:
- Growing share of EV and uncontrolled private charging lead to strongly differing electric load profiles in comparison to domestic basic load and increasing peaks in demand.

- The configuration in design of end devices offers high versatility of the domestic sector. Due to various possibilities of power transformation, the supply of final energy demand can be ensured by various kinds of delivered energy carriers which leads to the necessity of a multi-modal point of view.

- The composition of different domestic end devices for a whole residential area directly influences the amount and kind of delivered power. That relates to the necessary transition and distribution capacities for the three energy sectors electricity, gas and heat.

- The high degree of freedom in configuring end devices offers high flexibility in designing the whole energy system itself.

- The methodology can deliver guide values for end devices' technical design in terms of building extension with already existing infrastructure to support grid-assistive operation. For this, a coordination between the three grid operators and persons in charge of large-scale projects regarding rebuilding and expanding of residential areas is necessary so that costly expansion of one grid section due to reached capacity limits could potentially be avoided for the time being by utilizing already existing infrastructure of other energy carriers.

- Different strategies in development areas with a "green meadow" approach can be easily and effectively tested within the calculation tool to draw conclusions for the grid operators of the three energy sectors in terms of necessary grid expansion.

- The potential of "sector-coupling at home" in the domestic consumer sector can be involved in future holistic integrated energy system planning and operation.

Further research related to the presented method could especially focus on heuristically methods and mathematical optimization: The configuration parameters for the distribution of technical appliances would be the independent input variables and delivery power, resp. energy, the dependent result values. Using optimization algorithms should generate better configurations out of a random start configuration, based on minimization of the corresponding objective 
function or based on greedy algorithms using high sensitivity of the input parameters. Investigations could contain the already defined objectives, but also adding further objectives and combining and weighting them and so develop algorithms out of multi objective approaches can be part of future research. Moreover, impacts of single device efficiencies could be investigated in more detail via sensitivity analysis and so be able to estimate the potential of technical retrofit. Within future investigations, the method could be adapted to other consumer structures like the service or transportation sector. By combining the different consumer sectors whole urban structures can be modeled.

The method itself could be enlarged by further technical devices, for example in-house batteries for PV- oder FC-owners which also can release the electric sector, by not feeding all the generated power back to the grid. Also, individual efficiencies and engine-power classes could be taken into consideration to mirror the real existing diversity. In further improvement, partial load characteristics of the devices could be modeled to better represent their real behavior and generate more accurate results.

In conclusion, the presented manuscript depicts one part of an integrated energy system, more precisely, the domestic sector as one main consumer sector inside a whole energy system. Within the detailed explanation of the method, the high versatility of the domestic sector in terms of coupling the energy carriers and on-point energy transformation has been pictured. Satisfying domestic needs can be realized by various kinds of appliances with direct impact on the resulting power delivery, which directly leads to the necessary expansion capacities. The potential of flexibility in design of the domestic energy supply should be used as a chance to generate an important contribution to future integrated grid expansion methods.

\section{Contribution of individual authors to the creation of a scientific article (ghostwriting policy)}

Daniela Vorwerk: methodology, software, validation, investigation, resources, data curation, writing original draft preparation.

Detlef Schulz: Formal analysis, writing - review and editing, supervision, project administration, funding acquisition.

\section{Acknowledegements}

Thanks to the university for software deployment and to my colleague Marc Schumann for creating the fig- ures 2 and 8 and professional support.

$\begin{array}{ll}\text { Abbreviations } \\ \text { The following abbreviations are } \\ \text { manuscript: } \\ \text { abs } & \text { Absorber } \\ \text { amb } & \text { Ambient } \\ \text { B } & \text { Building } \\ \text { COP } & \text { Coefficient of performance } \\ \text { del } & \text { Delivery } \\ \text { DHG } & \text { District heating grid } \\ \text { dom } & \text { Domestic } \\ \text { el } & \text { Electric } \\ \text { EV } & \text { Electric vehicle } \\ \text { FC } & \text { Fuel cell } \\ \text { FE } & \text { Final energy } \\ \text { FH } & \text { Electric flow heater } \\ \text { GB } & \text { Gas boiler } \\ \text { HW } & \text { Hot water } \\ \text { in } & \text { Inside } \\ \text { NG } & \text { Natural gas } \\ \text { OP } & \text { Operating point } \\ \text { PV } & \text { Photovoltaic } \\ \text { R } & \text { Roof } \\ \text { RA } & \text { Residential area } \\ \text { SH } & \text { Space heating } \\ \text { ST } & \text { Solar thermal } \\ \text { STS } & \text { Solar thermal and storage } \\ \text { tot } & \text { Total } \\ \text { W } & \text { Wall } \\ & \end{array}$

\section{Creative Commons Attribution}

\section{License 4.0 (Attribution 4.0 \\ International , CC BY 4.0)}

This article is published under the terms of the Creative Commons Attribution License 4.0 https://creativecommons.org/licenses/by/4.0/deed.en US

\section{References: \\ [1] Deutsche Energie Agentur GmbH, dena-pilot study integrated energy transition (orig.: dena-Leitstudie Integrierte Energiewende, Impulse für die Gestaltung der Energiesysteme bis 2050), 2018}

[2] German National Academy of Sciences Leopoldina, acatech - National Academy of Science and Engineering, Union of the German Academies of Science and Humanities; Coupling the different energy sectors options for the next phase of the, 2018 energy transition 
[3] bdew, DVGW; Coupling infrastructure: The significance of gasinfrastructure and Powerto-Gas for the energy transition (orig: Infrastruktur verbinden, Die Bedeutung der Gasinfrastruktur und von Power-to-Gas für die Energiewende), 2018

[4] Olczak, M.; Piebalgs, A., Sector coupling: the new EU climate and energy paradigm?, 2018

[5] Franhofer ISI, Sector-coupling - Definition, chances an challenges (orig.: SektorkopplingDefinition, Chancen und Herausforderungen), Working Paper Sustainability and Innovation, No. S 01/2018

[6] Fokken, E.; Göttlich, S.; Kolb, O., Modeling and simulation of gas networks coupled to power grids. J Eng Math 119, pp. 217-239, 2019

[7] Shabanpour-Haghighi, A.; Reza Seifi, A., An Integrated Steady-State Operation Assessment of Electrical, Natural Gas, and District Heating Networks, IEEE Transactions on power systems, Vol 31, No. 5, September 2016

[8] Wu, J.; Yan, J.; Jia, H.; Hatziargyriou, N.; Djilali, N.; Sun, H., Integrated Energy Systems, Appl. Energy, 2016

[9] Hajimiragha, A.; Canizares, C.; Fowler, M.; Geidl, M.; Andersson, G., Optimal Energy Flow of Integrated Energy Systems with Hydrogen Economy Considerations University of Waterloo, ETH Zurich, Waterloo, Ontario, Canada Zurich, Switzerland, iREP Symposium- Bulk Power System Dynamics and Control - VII, Revitalizing Operational Reliability August 19-24, 2007, Charleston, SC, USA

[10] Bai, L.; Li, F.; Cui, H.; Jiang, T.; Sun, H.; Zhu, J., Interval Optimization based Operating Strategy for Gas-Electricity, Integrated Energy Systems Considering Demand Response and Wind Uncertainty, 2016

[11] Scheller, F.; Burgenmeister, B.; Kondziella, H.; Kühne, S.; Reichelt, D. G.; Bruckner, T.; Towards integrated multi-modal municipal energy systems: Anactor-oriented optimization approach, Applied Energy, 2018

[12] Pan, Z.; Wu, J.;Sun, H.;Guo, Q.; Abeysekera, M.; Quasi-dynamic Interactions and Security Control of Integrated Electricity and Heating Systems in Normal Operations, CSEE Journal of power and energy systems, Vol. 5, No. 1, March 2019
[13] Müller, C.; Falke, T.; Hoffrichter, A.; Wyrwoll, L.; Schmitt, C.; Trageser, M.; Schnettler, A.; Metzger, M.; Huber, M.; Küppers, M.; Most, D.; Paulus, S.; Heger, H.J., Planning and Evaluation of Multi-Modal Energy Systems for Decarbonization in Germany, 10th International Conference on Applied Energy (ICAE2018), Hong Kong, China, Energy Procedia , 2019

[14] Zeng, Q.; Zhang, B.; Fang, J.; Chen, Z., Coordinated operation of the electricity and natural gas systems with bi-directional energy conversion, Energy procedia, 2017

[15] Thiem, S.M.; Multi-modal on-site energy systems, Development and application of a superstructure-based optimization method for energy system design under consideration of part-load efficiencies, Doctoral thesis, Technical University of Munich, 2017

[16] Schaber, K., Steinke, F., Hamacher, T.: Managing Temporary Oversupply from Renewables Efficiently: Electricity Storage Versus Energy Sector Coupling in Germany, International Energy Workshop, Paris, 2013

[17] Brown, T.; Schlachtberger, D.; Kies, A.; Schramm, S.; Greiner, M.; Synergies of sector coupling and transmission reinforcement in a cost-optimised, highly renewable European energy system, Energy, 2018

[18] Crastan, V.; Electrical power supply 2: Power economy and climate protection, electricity industry and liberalization, power plant technology and alternative power supply, chemical storage (orig.: Elektrische Energieversogung: Energiewirtschaft und Klimaschutz, Elektrizitätswirtschaft und Liberalisierung, Kraftwerktechnik und alternative Stromversorgung, chemische Energiespeicherung), Springer-Vieweg, 2018

[19] Töpler, J; Lehmann, J., Hydrogen and fuel cell: technology and market perspective (orig.: Wasserstoff und Brennstoffzelle, Technologie und Marktperspektiven) ; Springer-Vieweg: Berlin Heidelberg, Germany, 2014

[20] Yao, L., Shen, J.-Y., Hong Lim, W.,Real-Time Energy Management Optimization for Smart Household, IEEE International Conference on Internet of Things (iThings) and IEEE Green Computing and Communications (GreenCom) and IEEE Cyber, Physical and Social Computing (CPSCom) and IEEE Smart Data (SmartData), 2016 
[21] Agnetis, A.; de Pascale, G.; Detti, P.; Vicino, A.,Load Scheduling for Household Energy Consumption Optimization, IEEE TRANSACTIONS ON SMART GRID, VOL. 4, NO. 4, DECEMBER 2013

[22] Schleich, J.; Faure, C.; Klobasa, M.,Persistence of the effects of providing feedback alongside smart metering devices on household electricity demand, Energy Policy, 2017

[23] Ge, S.; Li, J.; Liu, H.; Liu, X.; Wang, Y.; Zhou, H., Somestic Energy Consumption Modeling per Physical Characteristics and Behavioral Factors, Energy procedia 158, 2019

[24] Sugihara, H.; Komoto, J.; Tsuji, K., A Multiobjective Optimization Model for Determining Urban Energy Systems under Integrated Energy Service in a Specific Area

[25] Mollay, U.; Saringer-Bory, B., Smart Energy Supply Conception for the Urban Development Area of Aspern Seestadt (Vienna), 2016

[26] Keirstead, J.; Shah, N., Urban Energy Systems As An Integrated Approach, Routledge Taylor and Francis Group, London and New York, 2013

[27] Heuck, K.; Dettmann, K.-D.; Schulz, D., Electrical power supply: Generation, transition, distribution of electrical power for academic studies and practice (orig.: Elektrische Energieversorgung: Erzeugung, Übertragung und Verteilung elektrischer Energie für Studium und Praxis, Springer Vieweg, Springer Fachmedien Wiesbaden, 2013

[28] Zahoransky, R.; Power engineering: Systems for energy transformation, compact knowledge for academic studies and profession (orig.: Energietechnik: Systeme zur Energieumwandlung, Kompaktwissen für Studium und Beruf), Springer Fachmedien Wiesbaden, 2015

[29] Kurzweil, P.; Dietlmeier, O.K., Electrochemical storages: Supercapacitors, batteries, electrolysis-hydron, regulatory framework (orig.: Elektrochemische Speicher: Superkondensatoren, Batterien, ElektrolyseWasserstoff, Rechtliche Rahmenbedingungen), Springer-Vieweg, Springer Fachmedien Wiesbaden, 2018

[30] DIN EN 12831
[31] Enercity, Technical regulations for supply of district heat (orig: Technische Anschlussrichtlinie für die Versorgung mit Fernwärme (TAR)), 2019

[32] Fünfgeld, C.; Tiedemann, R., Step-by-step use of representative VDEW load profiles (orig: Anwendung der Repräsentativen VDEW-Lastprofile step - by - step); Lehrstuhl Energiewirtschaft, Brandenburgische Technische Universität Cottbus, 2000

[33] Dietmannsberger, M.; Meyer, M.F.; Schumann, M.; Schulz, D., Requirements on the electric grid concerning electromobility, especially electric buses, in Hamburg (orig.: Anforderungen an das Stromnetz durch Elektromobilität, insbesondere Elektrobusse, in Hamburg), Hamburg, 2016

[34] Quaschning, V., Renewable energy systems: Technology, computation, simulation (orig.: Regenerative Energiesysteme: Technologie, Berechnung, Simulation); Carl Hanser Verlag, Munich, Germany, 2015

[35] Stieglitz, R; Heinzel, V., Thermal solar energy: Basics, technology, application (orig.: Thermische Solarenergie: Grundlagen, Technologie, Anwendungen) ; Springer-Verlag: Berlin Heidelberg, Germany, 2012

[36] Zeisberger, J.; Contribution to energyefficient heating of tap water (orig: Beitrag zur energieeffizienten Trinkwassererwärmung Messtechnische Untersuchungen zur Bewertung und Optimierung von Trinkwassererwärmungssystemen), Technical University Munich, Faculty of architecture, 2017

[37] German meteorological service, test reference years data, 2015

[38] Gao, B.; Liu, X.; Zhu, Z., A Bottom-Up Model for Household Load Profile Based on the Consumption Behavior of Residents, MDPI energies, 2018

[39] Darvish, S.; Jordan, R.; Schumann, M.; Schulz, D.; Haupt H., Implementation of gridassistive charging- and load-management for EV on private space in the urban area of Hamburg (orig: Implementierung eines netzdienlichen Lade- und Lastmanagements für Elektrofahrzeuge auf Privatflächen im Stadtgebiet Hamburg), Hamburg's contributions to technical climate protection (orig: Hamburger Beiträge zum technischen Klimaschutz), 2019 
[40] Jahic, A.; Eskander, M.; Schulz, D., Charging Schedule for Load Peak Minimization on Large-Scale Electric Bus Depots, MDPI applied science, 2019

[41] Crastan, V.; Electrical power supply: Grid components, modeling, stationary behavior, dimensioning, circuitry and shielding methods (orig.: Elektrische Energieversorgung 1, Netzelemente, Modellierung, stationäres Verhalten, Bemessung, Schalt- und Schutztechnik), 2012

[42] Bschorer, S.; Technical fluid dynamics (orig: Technische Strömungslehre, Lehr- und Übungsbuch 11. Auflage), Springer Vieweg, Wiesbaden, Germany, 2018

[43] Floß, A.; Dietrich, C.,Optimal integration of buffer storages (orig: Optimierte Integration von Pufferspeichern), Institut für Gebäudeund Energiesysteme, Hochschule Biberach

[44] Sterner, M.; Stadler, I., Energy storages: Demand, technology, integration (orig.: Energiespeicher: Bedarf, Technologien, Integration), Springer-Vieweg, 2014

\section{Appendix}

\section{Modeling of hot water storage}

The storage for tap water is modeled as an ideal stratified storage with two zones of different temperature level. That does not refer to the reality [43] but reflects the system of a tap water storage better than the model of an ideal mixed storage. Due to the use of solar thermal energy at low operating temperature the solar heat is than more effectively storable. In the following the model is presented in detail. Heat losses of the storage are neglected.

The regulation always provides a ratio of $40 \%$ of the full volume constantly at the higher temperature $T_{\mathrm{h}}$ at e.g. $60^{\circ} \mathrm{C}$ to avoid legionella. The temperature $T_{1}$ in the storage's lower part differs, but is limited up to 60 ${ }^{\circ} \mathrm{C}$, because at higher temperature it can lead to chalk [35, 44]. The state, when the whole water inside of the storage is at the temperature level of $60{ }^{\circ} \mathrm{C}$ describes the completely charged state of the storage. $T_{1}$ is at least as high as the inlet temperature of the incoming fresh water $T_{\mathrm{c}}$, here assumed as $10^{\circ} \mathrm{C}$. The absolute lowest accepted state of the storage is at $60^{\circ} \mathrm{C}$ inside the upper part and $10^{\circ} \mathrm{C}$ at the part below. That state represents the minimum charging level. model of the storage is visualized in figure 8 .

For a known demand of tap water $\dot{V}$ at a desired temperaturelevel, lower than $60^{\circ} \mathrm{C}$ The desired temperature can be reached by mixing the stored water with fresh water of the temperature $T_{\mathrm{c}}$. Considering

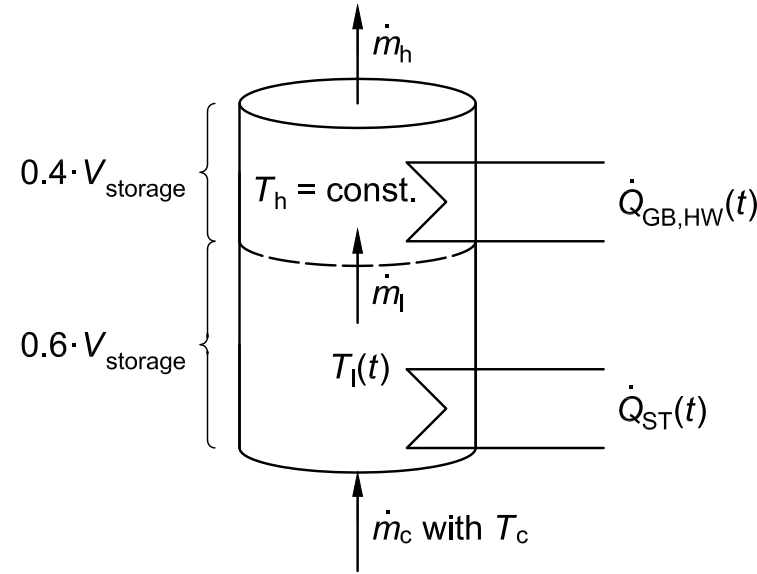

Fig. 8: Figure of the ideal stratified hot water storage.

water as incompressible fluid with constant density ( $\rho=$ const.), the water's mass flow at the desired temperature $T_{\mathrm{m}}$ can be delivered by mixing hot water of $60^{\circ} \mathrm{C}$ and untreated fresh water of $10^{\circ} \mathrm{C}$. Assuming a constant heat capacity for water $\left(c_{p}=4.2 \frac{\mathrm{kJ}}{\mathrm{kgK}}\right)$ the necessary mass flow out of the storage at the higher temperature level can be calculated by

$$
\dot{m}_{\mathrm{HW}, \mathrm{h}}(t)=\frac{\dot{m}}{T_{\mathrm{h}}-T_{\mathrm{c}}} .
$$

For the time $t$ the heat flow out of the storage at the higher temperature $T_{h}$ can be calculated by

$$
\dot{Q}_{\mathrm{HW}}(t)=\dot{m}_{\mathrm{HW}, \mathrm{h}}(t) \cdot c_{p}\left(T_{\mathrm{h}}-T_{\mathrm{c}}\right) .
$$

In this modeling it is simplifying assumed that the delivery of fresh water or pumps do not need any extra energy.

For the investigation of solar thermal exploitation at every timestep $t$ it has to be determined if solar power $\dot{Q}_{\mathrm{ST}}$ is stored, rolled out of the storage, or even the additional conventional heat source is necessary. In this ideal stratified model, the outflowing mass flow $\dot{m}_{\mathrm{HW}, \mathrm{h}}(t)$ has to be replaced by raising up of mass from the lower to the higher temperature level. This happens due to the yield of a heat source.

The capacity inside the storage at every time is devided into the two zones. In the upper level it is, based on the cold water temperature, given by

$Q_{\mathrm{h}}=m_{\mathrm{h}} \cdot c_{p} \cdot\left(T_{\mathrm{h}}-T_{\mathrm{c}}\right)=0.4 \cdot V_{\text {storage }} \cdot \rho\left(T_{\mathrm{h}}-T_{\mathrm{c}}\right)$.

According to the already remarked condition of a constant temperature $T_{\mathrm{h}}$, the capacitiy in the upper part is always the same.

In the lower part, the state of charging $Q_{1}(t)$ varies in dependency of the water temperature in the lower 
part. It can be determined by

$$
\begin{aligned}
& Q_{1}(t)=m_{\mathrm{c}} \cdot c_{p} \cdot\left(T_{1}(t)-T_{\mathrm{c}}\right) \\
&=0.6 \cdot V_{\text {storage }} \cdot \rho \cdot c_{p} \cdot\left(T_{1}-T_{\mathrm{c}}\right) .
\end{aligned}
$$

The maximum temperature is limited to $T_{1}=T_{\mathrm{h}}$, so the maximum capacity of the storage is limited to

$$
Q_{1, \max }=0.6 \cdot V_{\text {storage }} \cdot \rho \cdot c_{p} \cdot\left(T_{\mathrm{h}}-T_{\mathrm{c}}\right)
$$

and the minimum heat which only insists of untreatend fresh water based on the lower temperature of delivered water, $T_{\mathrm{c}}$, is $Q_{1, \min }=0$.

Storage balance To fulfill the condition that always at least $40 \%$ of the total volume is at the temperature $T_{\mathrm{h}}$ and to keep the storage at its current volume of water, the removed mass flow $\dot{m}_{\mathrm{HW}, \mathrm{h}}(t)$ by the consumer has to be replaced by fresh water $\dot{m}_{\mathrm{c}}$, but it is on the low temperature level $T_{\mathrm{c}}$. The mass balance

$$
\dot{m}_{\mathrm{h}}(t)=\dot{m}_{1}(t)=\dot{m}_{\mathrm{c}}(t)
$$

for the "rising" masses up to the next higher temperature level has to be fulfilled at every time $t$. It is based on the imagination of rising up mass cubics from the fresh level (c) to the low level (1) and from the low level (l) to the high level (h).

The heat power to replace the missing mass in the upper part is named as $\dot{Q}_{\text {replace,h }}$ and shall now be defined by the heat flow

$$
\dot{Q}_{\text {replace, } \mathrm{h}}(t)=\dot{m}_{\mathrm{l}}(t) \cdot c_{p} \cdot\left(T_{\mathrm{h}}-T_{1}(t)\right) .
$$

and the heat power which has to be given to the inflowing fresh water with the temperature $T_{c}$ to get to constant temperature $T_{1}(t)$ is defined as

$$
\dot{Q}_{\text {replace, }, 1}(t)=\dot{m}_{\mathrm{c}}(t) \cdot c_{p} \cdot\left(T_{1}(t)-T_{\mathrm{c}}\right) .
$$

Those are dependent on the storage's charging level, represented by the temperature $T_{1}(t)$ in the lower part.

If the exactly same heat power $\dot{Q}_{\text {in }}$ (e.g. prodced by solar thermal or additional source) can be given back to the system.

If the equation

$$
\dot{Q}_{\mathrm{HW}}(t)=\dot{Q}_{\text {replace,h }}(t)+\dot{Q}_{\text {replace, },}(t)
$$

is valid, the state of the storage does not change during that time step.

Case 1: Store solar thermal power In case of higher or equal solar power $\dot{Q}_{\mathrm{ST}}(t)$ compared to the demand $\dot{Q}_{\mathrm{HW}}(t)$, so that the inequation

$$
\dot{Q}_{\mathrm{ST}}(t) \geq \dot{Q}_{\text {replace,h }}(t)+\dot{Q}_{\text {replace,h }}(t)
$$

is valid, leads to the equation

$$
\begin{aligned}
\int_{t_{n}}^{t_{n+1}} \dot{Q}_{\mathrm{ST}}(t) \mathrm{d} t=\int_{t_{n}}^{t_{n+1}}\left(\dot{Q}_{\text {replace, } \mathrm{h}}\right. & \left.+\dot{Q}_{\text {replace, } \mathrm{h}}\right) \mathrm{d} t \\
& +\Delta Q_{1}
\end{aligned}
$$

with the storable heat energy $\Delta Q_{1}$. Because of the knowledge of the produced solar power $\dot{Q}_{S T}$ and the fixed necessary heat $\dot{Q}_{\text {replace,h }}(t)$ and $\dot{Q}_{\text {replace,h }}(t)$, the excess heat $\Delta Q_{1}$ can be calculated with equation 60 . Its is assumed that only the lower part of the storage is heated up, but the higher part temperature $T_{\mathrm{h}}$ stays constant. The stored heat energy in the lower part between two timesteps is defined by

$$
\begin{aligned}
& \Delta Q_{1}=Q_{1}\left(t_{2}\right)-Q_{1}\left(t_{1}\right) \\
& =0.6 \cdot V_{\text {storage }} \cdot \rho \cdot c_{p} \cdot\left(T_{1}\left(t_{2}\right)-T_{1}\left(t_{1}\right)\right)
\end{aligned}
$$

and by eliminating $T_{1}\left(t_{2}\right)$ inside of equation 61 , the temperature at the lower level can be calculated for the next timestep.

Case 2: Discharging storage In case of lower solar thermal power in comparison to the needed power, so that the inequation

$$
\dot{Q}_{\mathrm{ST}}(t) \leq \dot{Q}_{\text {replace,h }}(t)+\dot{Q}_{\text {replace, } \mathrm{h}}(t)
$$

but also the inequation

$$
\dot{Q}_{\mathrm{ST}}(t) \geq \dot{Q}_{\text {replace,h }}(t)
$$

is valid, it is assumed that the mass flow $m_{1}$ can be heated up to the higher temperature $T_{\mathrm{h}}$ by the solar power. That assumption is valid under the premise that the temperature of the heat carrier medium inside the absorber is entering the storage's heat exchanger at $65{ }^{\circ} \mathrm{C}$ with a controlled mass flow.

Because of inequation 62 the solar power dies not suffice to heat the replaced mass flow at the lower level. The reduced heat power, given to the rising mass cubic, $\dot{Q}_{\text {replace, 1, red }}(t)$, can be calculated by

$$
\dot{Q}_{\text {replace, 1, red }}(t)=\dot{Q}_{\mathrm{ST}}(t)-\dot{Q}_{\text {replace,h }}(t)
$$

The reduced temperature $T_{1, \text { red }}$ of the incoming fluid is then

$$
T_{1, \text { red }}(t)=\frac{\dot{Q}_{\text {replace, }, \text { red }}(t)}{\dot{m}_{\mathrm{c}}(t) c_{p}}+T_{\mathrm{c}}<T_{1}(t) .
$$

The mixed new temperature $T_{1}\left(t_{2}\right)$ is then

$$
\begin{aligned}
& T_{1}\left(t_{2}\right)=\frac{\int_{t_{1}}^{t_{2}} \dot{m}_{c}\left(t_{1}\right) \mathrm{d} t \cdot T_{1, \text { red }}\left(t_{1}\right)}{0.6 \cdot V_{\text {storage }} \cdot \rho} \\
& +\frac{\left(0.6 \cdot V_{\text {storage }} \cdot \rho-\int_{t_{1}}^{t_{2}} m_{1}\left(t_{1}\right)\right) T_{1}\left(t_{1}\right)}{0.6 \cdot V_{\text {storage }} \cdot \rho}<T_{1}(t) .
\end{aligned}
$$


The decreasing of the temperature implies discharging of the storage. The lost heat between two timesteps is

$$
\Delta Q_{1}=0.6 \cdot V_{\text {storage }} \rho c_{p}\left(T_{1}\left(t_{1}\right)-T_{1}\left(t_{2}\right)\right)<0 .
$$

Case 3: Additional heat source necessary In case that the solar power is not enough to replace the mass in the upper part of the storage, resp. the inequation

$$
\dot{Q}_{\mathrm{ST}}(t) \leq \dot{Q}_{\text {replace, }}(t)
$$

is valid, all of the solar thermal heat is used to heat up the massflow $m_{1}$ to the the high temperature level to a temperature level as high as possible. It is given by

$$
\dot{Q}_{\text {replace,h,red }}(t)=\dot{Q}_{\mathrm{ST}}(t) .
$$

The reduced reached temperature level is

$$
T_{\mathrm{h}, \text { red }}(t)=\frac{Q_{\mathrm{ST}}(t)}{\dot{m}_{1}(t) c_{p}}+T_{1}(t)<T_{\mathrm{h}} .
$$

That means, temperature level $T_{h}$ could not be held inside of the upper part. It would lead to a given a mixed temperature by

$$
\begin{aligned}
& T_{\mathrm{h}, \text { mix }}\left(t_{2}\right)=\frac{\int_{t_{1}}^{t_{2}} \dot{m}_{1}\left(t_{1}\right) \mathrm{d} t \cdot T_{\mathrm{h}, \text { red }}\left(t_{1}\right)}{0.4 \cdot V_{\text {storage }}} \\
& +\frac{\left(0.4 \cdot V_{\text {storage }} \cdot \rho-\int_{t_{1}}^{t_{2}} \dot{m}_{\mathrm{h}}\left(t_{1}\right) \mathrm{d} t\right) T_{\mathrm{h}}\left(t_{1}\right)}{0.4 \cdot V_{\text {storage }} \cdot \rho}<T_{\mathrm{h}} .
\end{aligned}
$$

To now heat up the upper area to the desired temperature $T_{\mathrm{h}}$, as already mentioned as a boundary condition, an additional heat source is necessary.

$\int_{t_{1}}^{t_{2}} \dot{Q}_{\text {conv. }}\left(t_{1}\right) \mathrm{d} t=0.4 \cdot V_{\text {storage }} \cdot \rho \cdot c_{p}\left(T_{\mathrm{h}}-T_{\mathrm{h}, \text { mix }}\left(t_{2}\right)\right)$.

The lower part of the storage is not heated up by the additional source, but will decrease to a mixed temperature (see equation 66) and the change in the heat capacity in the lower part is $\Delta Q_{1}$.

\section{Properties of the exemplary execution}

The chosen properties of the exemplary development area are shown in table 5 .

In a first approximation, all devices have the same efficiencies and nominal power to ensure the corresponding demand. The technical equipment's properties are given in table 6 .

In addition, some further assumptions are made:

- The considered residential area consists of $N=100$ households.
- The used technologies of the same type are all the same size, design and constant efficiency.

- Every house is considered equal with the parameters given in table 5. That leads to the same demand of space heating.

- Every household connected to the district heating grid uses it for heating usage water and also for heat space. So it is $n_{\mathrm{DHG}, \mathrm{HW}}=n_{\mathrm{DHG}, \mathrm{SH}}$, resp $y=z$ valid.

- Households with a NG boiler use it only for space heating or for space heating and warm water, but not only for warm water. This leads to the condition $n_{\mathrm{GB}, \mathrm{SH}} \geq n_{\mathrm{GB}, \mathrm{HW}}$, resp $g \geq e$.

- Fuel cell systems are all run heat leaded with a constant factor $\psi_{\mathrm{FC}}$. Households with an installed fuel cell system use it for space heating and the heating of usage water. That says, that at every timestep the fuel cell has to ensure the own space heating demand and demand of warm water.

- Households cannot own the full capicity of solar thermal and PV technology, because it is limited by the roof area $A_{\mathrm{R}}$. The sum of the ratios $\zeta_{\mathrm{PV}, \mathrm{i}}$ of $\mathrm{PV}$ covering and $\zeta_{\mathrm{PV}, \mathrm{i}}$ of solar thermal covering are less or equal than 1 .

- The calculation is executed stationary for a simulated time period of one year with intervals of one hour.

- The structure of buildings and the number of inhabitants per household is assumed equal and constant.

- All households with use of solar thermal power for tap water heating own a strorage and a gas boiler as the conventional heat source.

- The solar thermal circle is temperaturecontrolled with a constant return absorber temperature of $T_{\mathrm{abs}}=65^{\circ} \mathrm{C}$.

- Space heating is only necessary for ambient temperature values below the limit temperature $T_{\mathrm{amb}, \text { limit }}$ and only in the winter and transition time period. Deactivating of heating devices at night and instationary heating processes are not considered.

- The demands arise synchronously according to the demand data in figure 12 .

- All heat exchangers (STS, GB, DHG) in the system behave with sufficient temperature differences. The heat from the primary medium can be transferred completely to the second medium. 
Table 5: Properties of the exemplary residential area.

\begin{tabular}{|c|c|c|}
\hline Variable & Explanation & Value \\
\hline$N$ & Number of residences & 100 \\
\hline$n_{\mathrm{P}}$ & $\begin{array}{l}\text { Average number of persons per } \\
\text { household }\end{array}$ & 4 \\
\hline$V_{\mathrm{HW}, \mathrm{p}}$ & $\begin{array}{l}\text { Hot water demand at } 45{ }^{\circ} \mathrm{C} \text { per } \\
\text { person and day }\end{array}$ & $35 \mathrm{~L}$ \\
\hline$V_{\mathrm{B}}$ & Volume of building & $416 \mathrm{~m}^{3}$ \\
\hline$A_{\mathrm{B}}$ & Total outer building area & $347 \mathrm{~m}^{2}$ \\
\hline$A_{\mathrm{R}}$ & Roof area & $0.23 \cdot A_{\mathrm{B}}$ \\
\hline$A_{\mathrm{W}}$ & Wall area & $0.65 \cdot A_{\mathrm{B}}$ \\
\hline$A_{\text {Window }}$ & Window area per building & $0.12 \cdot A_{\mathrm{B}}$ \\
\hline$k_{\mathrm{R}}$ & Heat flow coefficient for the roof & $0.16 \frac{\mathrm{W}}{\mathrm{m}^{2} \mathrm{~K}}$ \\
\hline$k_{\mathrm{W}}$ & $\begin{array}{l}\text { Heat flow coefficient for the outer } \\
\text { wall }\end{array}$ & $0.15 \frac{\mathrm{w}^{\mathrm{K}}}{\mathrm{m}^{2} \mathrm{~K}}$ \\
\hline$k_{\text {Window }}$ & Heat flow coefficient for windows & $1.0 \frac{\mathrm{W}}{\mathrm{m}^{2} \mathrm{~K}}$ \\
\hline$n_{\text {airexchange }}$ & Air exchange rate for the building & $0.7 \frac{1}{h}^{2} \mathrm{~K}$ \\
\hline$T_{\text {in }}$ & Desired inner room temperature & $20^{\circ} \mathrm{C}$ \\
\hline$T_{\mathrm{amb}, \mathrm{limit}}$ & $\begin{array}{l}\text { Lower ambient temperature } \\
\text { threshold }\end{array}$ & $15^{\circ} \mathrm{C}$ \\
\hline$V_{\text {storage }}$ & $\begin{array}{l}\text { Hot water storage volume for ST } \\
\text { use }\end{array}$ & $n_{\mathrm{P}} \cdot V_{\mathrm{HW}, \mathrm{p}} \cdot 10^{-3} \mathrm{~m}^{3}$ \\
\hline$T_{\mathrm{h}}$ & Temperature at hot part of storage & $60^{\circ} \mathrm{C}$ \\
\hline$l_{\mathrm{EV}}$ & $\begin{array}{l}\text { Average dridaily driving route for } \\
\text { EV }\end{array}$ & $\frac{55 \mathrm{~km}}{d}$ \\
\hline
\end{tabular}

Table 6: Overview over the applied properties of technical devices.

\begin{tabular}{ll}
\hline Device & Properties \\
\hline PV cell & $\eta_{\mathrm{o}}\left(25^{\circ} \mathrm{C}\right)=0.215$ \\
& $\tau_{\mathrm{PV}}=-0.004$ \\
& $P_{\mathrm{el}, \mathrm{max}}=110 \frac{\mathrm{W}_{\mathrm{p}}}{\mathrm{m}^{2}}$ \\
FC & $\eta_{\mathrm{el}}=0.38$ \\
& $\eta_{\mathrm{th}}=0.55$ \\
& $P_{\mathrm{el}}=\psi_{\mathrm{FC}}=0.7$ \\
Electric Flow heater & $\eta=0.99$ \\
Gas boiler & $\eta=0.93$ \\
Solar Thermal cell & $\eta_{\mathrm{o}}\left(25^{\circ} \mathrm{C}\right)=0.82$ \\
& $T_{\mathrm{abs}, \mathrm{out}}=65{ }^{\circ} \mathrm{C}$ \\
& $k_{\mathrm{tot}}^{*}=3.8 \frac{\mathrm{W}}{\mathrm{m}^{2} \mathrm{~K}}$ \\
Heat pump & $k_{1}=0.03 \frac{\mathrm{W}}{\mathrm{m}^{2} \mathrm{~K}}$ \\
Electric vehicle & $C O P=4.0$ \\
& $\eta_{\mathrm{EV}, \text { charge }}=1.0$ \\
& $P_{\mathrm{EV}, \text { charge }}=3.7 \mathrm{~kW}$ \\
& $e_{\mathrm{EV}}=\frac{20 \mathrm{kWh}}{100 \mathrm{~km}}$ \\
\hline
\end{tabular}

- The energy consumption of every EV is considered with $20 \mathrm{kWh} / 100 \mathrm{~km}$ and a vehicle's average route is $55 \mathrm{~km}$ per day, hence the full amount of energy in every charging circle is $11 \mathrm{kWh}$ every day. The charging process is not differentiated in weekdays and weekends.

\section{Creative Commons Attribution License 4.0 (Attribution 4.0 International, CC BY 4.0)}

This article is published under the terms of the Creative Commons Attribution License 4.0

https://creativecommons.org/licenses/by/4.0/deed.en_US 


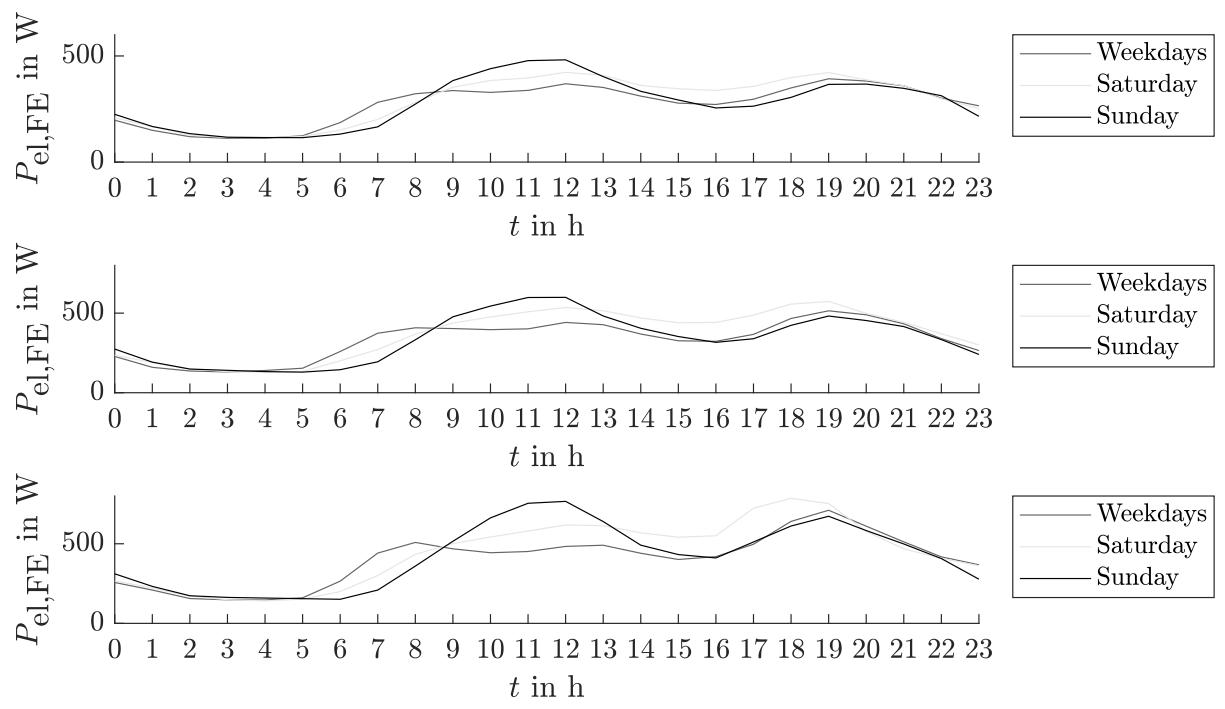

Fig. 9: Assumption of electric power demand for one household (a) Summer (b) Transition period (c) Winter according to [32], normalized to $3000 \mathrm{kWh}$ per year and household.

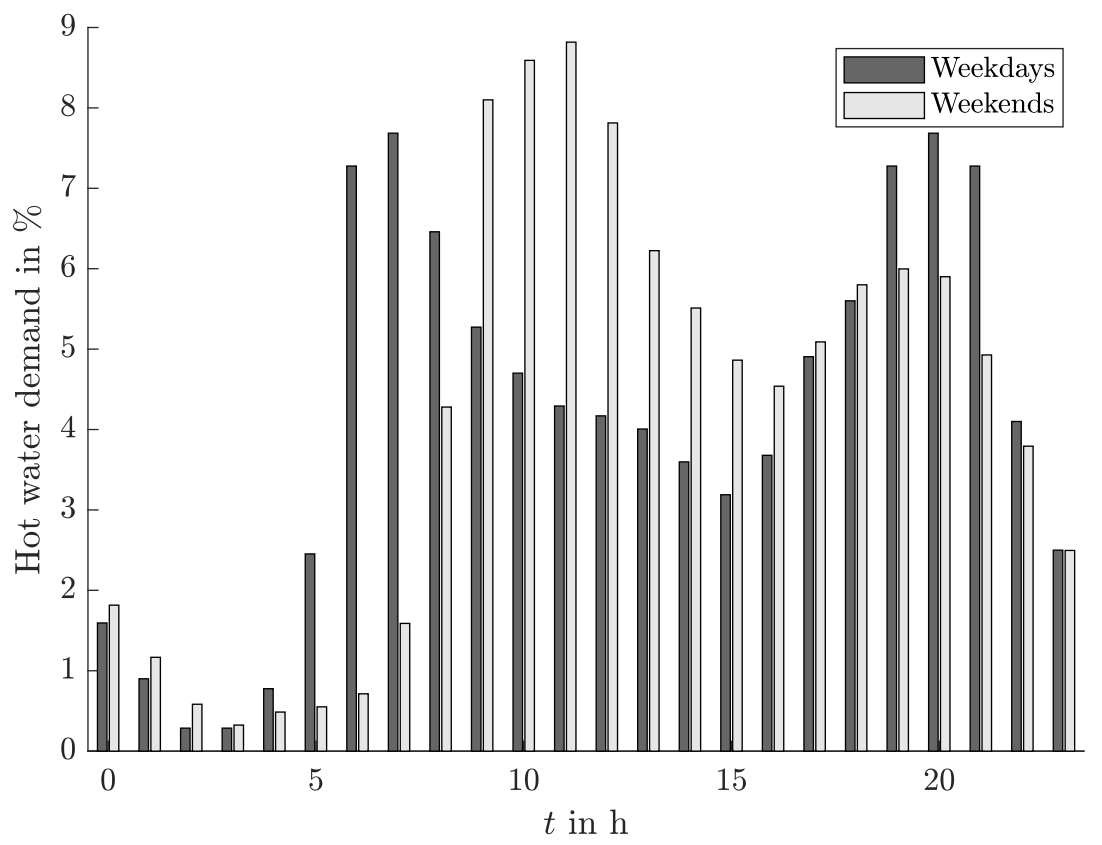

Fig. 10: Amount of hot water demand in the domestic sector according to [36]. 

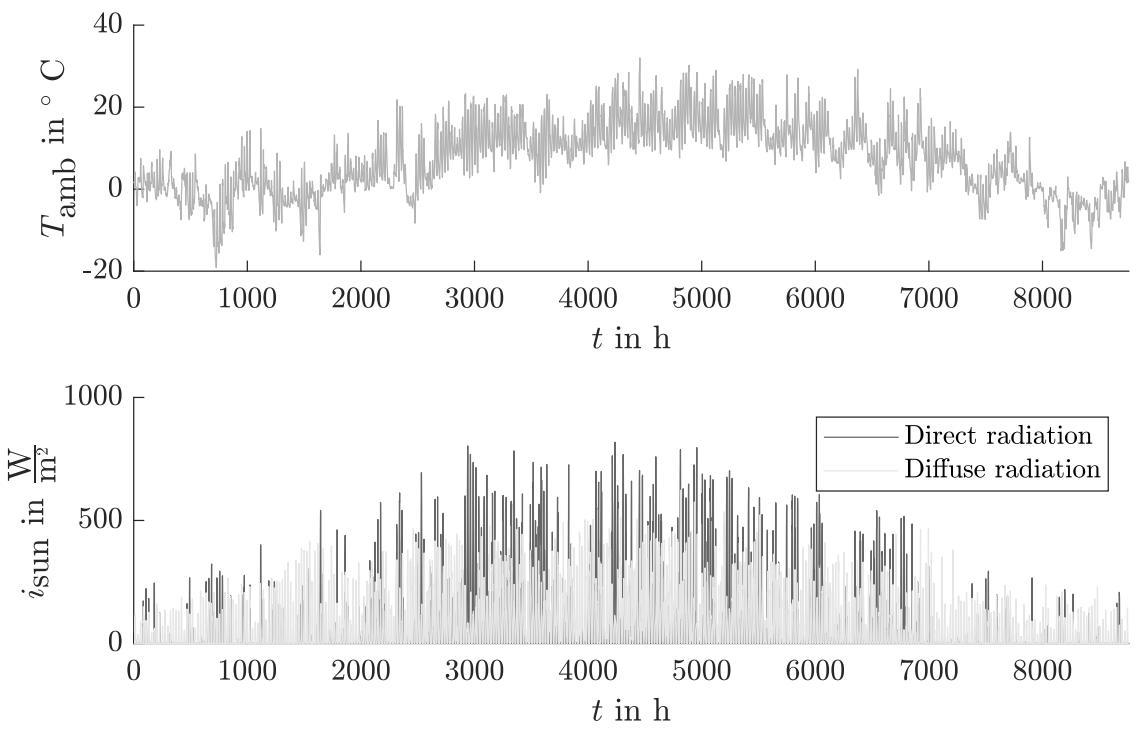

Fig. 11: (a) Ambient temperature in ${ }^{\circ} \mathrm{C}$ accroding to (b) Diffuse and direkt radiation in $\frac{\mathrm{W}}{\mathrm{m}^{2}}$ on a horizontal area according to [37].
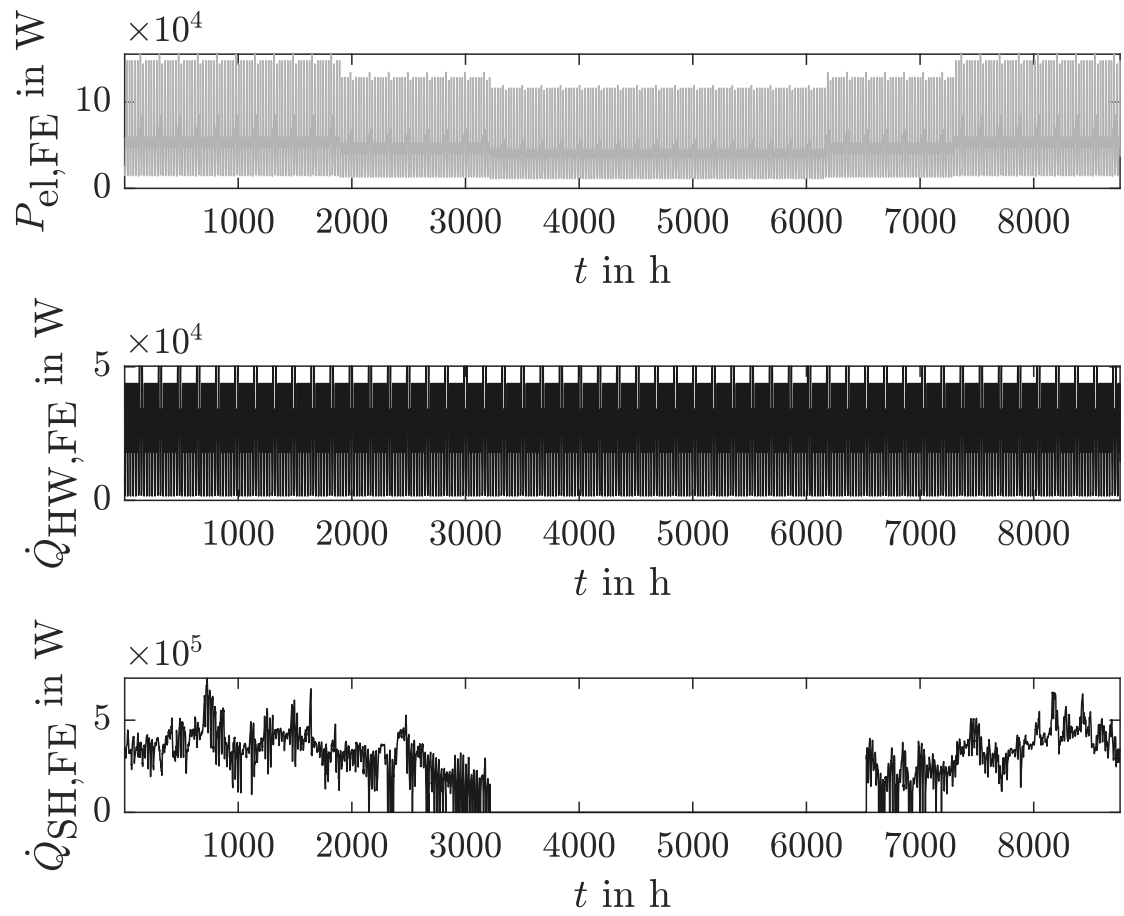

Fig. 12: Annual final energy demand for considered exemplary residential area with $N=100$ households. (a) Electric demand with basic load and a EV share of $v=0.5$ (b) Hot water demand (c) Space heating demand. 